Portland State University

PDXScholar

1980

\title{
A survey of carryover practices of public school clinicians in Oregon
}

Joan Marie Cranmer Polson

Portland State University

Follow this and additional works at: https://pdxscholar.library.pdx.edu/open_access_etds

Part of the Clinical and Medical Social Work Commons, and the Speech Pathology and Audiology Commons

Let us know how access to this document benefits you.

\section{Recommended Citation}

Polson, Joan Marie Cranmer, "A survey of carryover practices of public school clinicians in Oregon" (1980). Dissertations and Theses. Paper 2972.

https://doi.org/10.15760/etd.2964

This Thesis is brought to you for free and open access. It has been accepted for inclusion in Dissertations and Theses by an authorized administrator of PDXScholar. Please contact us if we can make this document more accessible: pdxscholar@pdx.edu. 
AN ABSTRACT OF THE THESIS OF Joan Marie Cranmer Polson for the Master of Science in Speech Communication, with an emphasis in Speech Pathology/ Audiology, presented April 29, 1980.

Title: A Survey of Carryover Practices of Public School clinicians in Oregon.

APPROVED BY MEMBERS OF THE THESIS COMMITTEE:

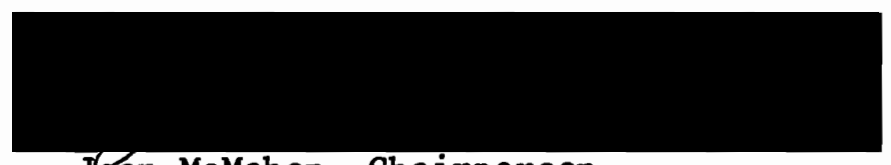

Jban McMahon, Chairperson

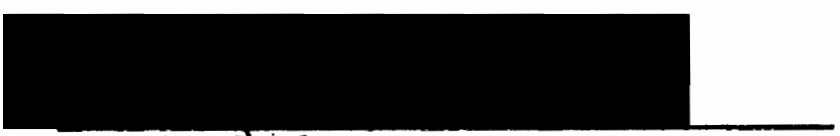

Mary E. Abrdon

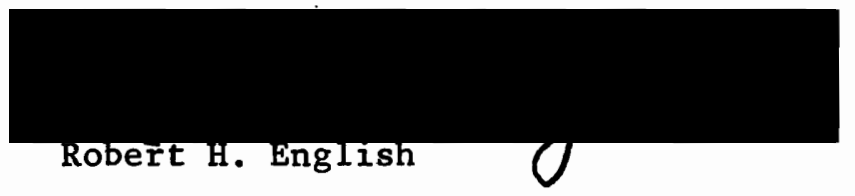

Clinicians report that carryover management is one of the most difficult and time consuming problems they face (Johnson, 1972) yet the literature offers little data to assist clinicians in determining what methodologies should be used and which are effective in facilitating carryover. The purpose of this investigation was to determine the type of methodologies utilized by public school clinicians in Oregon to 
facilitate carryover with clients originally diagnosed as having articulation disorders. A secondary question dealt with the perceived effectiveness of these methodologies.

A description of current practices and trends in articulation management programs was derived from answers to a questionnaire sent to 200 public school clinicians in Oregon. One hundred and twenty-six of the 159 questionnaires returned were used in the tabulation of results.

Clinicians in Oregon participating in this study employ a variety of methodologies in their carryover programs. Four management techniques were reported used by 70 per cent or more of the respondents to this survey: client self-evaluation; client completion of homework assignments; client works with individuals other than the clinician; and, client practices until responses are automatic. The four most effective management techniques were: client self-evaluation; client practices until responses are automatic; following a structured behavior modification program; and, client works with individuals other than the clinician. The individuals most often included in management were classroom teachers and the client's parents. The most effective individuals, however, were the client's parents and speech aides. Clinician developed carryover programs were reported to be the most often used as well as the most effective material or equipment. Discrepancies in data due to questionnaire design should be studied further. 
A SURVEY OF CARRYOVER PRACTICES OF PUBLIC SCHOOL CLINICIANS IN OREGON

by

JOAN MARIE CRANMER POLSON

A thesis submitted in partial fulfillment of the requirements for the degree of

MASTER OF SCIENCE IN SPEECH COMMUNICATION:

with an emphasis in

SPEECH PATHOLOGY/AUDIOLOGY

Portland State University

1980 
TO THE OFFICE OF GRADUATE STUDIES AND RESEARCH:

The members of the Committee approve the thesis of Joan Marie Cranmer Polson presented April 29, 1980.

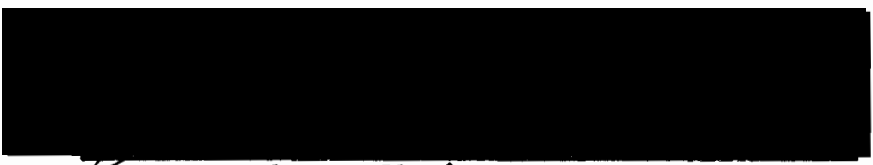

Joan McMahon, Chairperson

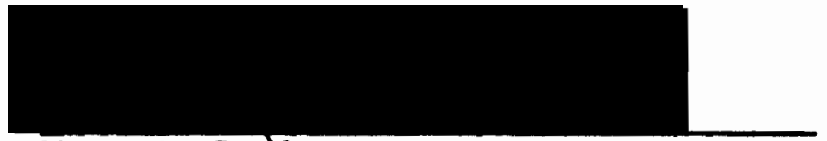

Mary E. Gordion

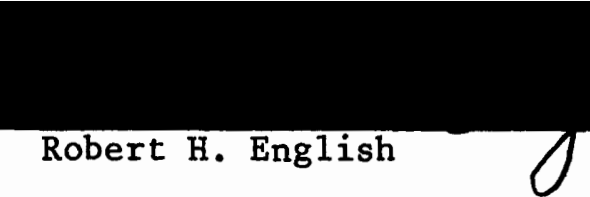

APPROVED :

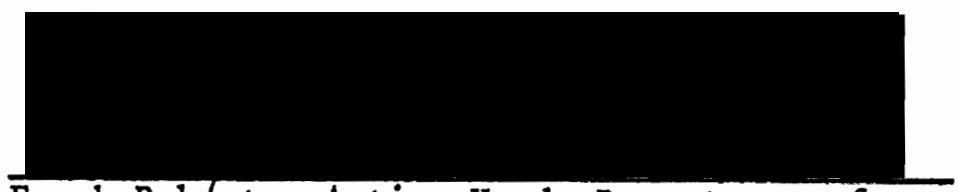

Frank Roberts, Acting Head, Department of Speech Communication

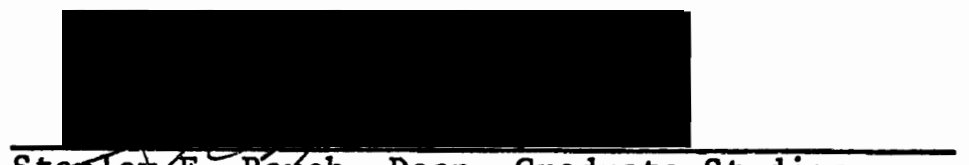

Stanley E. Raueh, Dean, Graduate Studies and Research 


\section{ACKNOWLEDGMENTS}

I wish to extend my gratitude and sincere appreciation to Joan McMahon, the chairperson of my thesis committee. Her guidance, instruction and absurd deadlines made this thesis a reality. My thanks also to Mary Gordon, Robert English and Cathleen Smith, members of my committee, and to Robert Casteel and Ted Grove for their most helpful comments and suggestions.

I would like to dedicate this thesis to two very special people: my mother, Lucy, who always had faith in me, and my husband, Dick, who was my counselor and mentor.

Finally, a special thanks to my colleagues John Hanlan, Karen Matthew, Carol Middleton, Sandy Neuburger and Margo Keller whose influence has enriched me professionally as well as personally. 
TABLE OF CONTENTS

Page

ACKNOWLEDGEMENTS ....................... . .

LIST OF TABLES . . . . . . . . . . . . . . . . . . . . vii

LIST OF FIGURES . . . . . . . . . . . . . . . . . . . . . viii

CHAPTER

I INTRODUCTION AND PURPOSE

Introduction ................... . . 1

Statement of Purpose............... 2

Definition of Terms ............. 3

II REVIEW OF THE LITERATURE . . . . . . . . . . . . 4

Carryover .. . . . . . . . . . . . . . 4

Methods for Facilitating Carryover........ 5

Individuals in the Child's Environment . . . . 6

Management Techniques .......... 9

Materials and/or Equipment ......... 12

Transfer of Training . . . . . . . . . . 13

III METHODS AND PROCEDURES . . . . . . . . . . . 15

Methods ................... 15

Subjects ................. 15

Instrumentation . . . . . . . . . 15

Procedures ...... . . . . . . . . 17

Data Coding ................ 18

Analysis of the Data... . . . . . . 18

Demographic Data

Management Practices

Use of Carryover Methodologies

Perceived Effectiveness of the Carryover Methodologies

IV RESULTS AND DISCUSSION . . . . . . . . . . . . 20

Results .................... 20

Methodologies Used............ 20 
Management Techniques

Individuals in the Child's Environment

Materials and/or Equipment

Effectiveness of Reported Methodologies . .

Management Techniques

Individuals in the Client's Environment

Materials and/or Equipment

Management Practices... . . . . . . . 25

Discussion . . . . . . . . . . . . . 25

Demographic Data . . . . . . . . . . . . 26

Methodologies and Their Effectiveness . . . . . 28

Methods Used in the Clinic... . . . . . 28

Auditory Discrimination Training

Client Self-evaluation

Practice Until Responses Are Automatic

Creative Dramatics

Practice under Emotional Conditions

An Emerging. Hierarchy in Carryover

Behavior Modification

Other Methods Reported by the Clinicians

Methods Used Outside the Clinic . . . . . .

Working with the Client Outside the

Clinic

Clinician Developed Homework

Client Developed Homework

Reminders in the Client's Environment

Language Arts Programs

Client Works with Others

People Included in the Management Program . .

Parents

Classroom Teachers

Client's Peers

Speech Pals

Classroom Aides

Speech Aides

Other Individuals Involved in Carryover

Hierarchy of Individuals

Materials and/or Equipment .........

Programmed Materials

Tape Recorders

Workbooks

Other Materials or Equipment

Reported Problems in Attaining Carryover . . . .

Client Attitude . . . . . . . . . . . 54

Follow Through and Support by Outside

Individuals ............ . 54

Intervention Programs . . . . . . . . . 55

Time

Caseload Size

Onset of Management

Program Emphasis 
Management Practices . . . . . . . . . . 57

V SUMMARY AND IMPLICATIONS . . . . . . . . . . . . 62

Summary . . . . . . . . . . . . . . 62

Research Implications . . . . . . . . . . . . 63

Clinical Implications . . . . . . . . . . 64

The University Setting . . . . . . . . . 64

The Public School Setting . . . . . . . 65

BIBLIOGRAPHY . . . . . . . . . . . . . . . . . . 67

APPENDICES . . . . . . . . . . . . . . . . . . 70

A DEMOGRAPHIC DATA . . . . . . . . . . . . . . 70

B ARTICULATION CARRYOVER QUESTIONNAIRE . . . . . . . . 71

C COVER LETTER AND INFORMED CONSENT FORM . . . . . . . . 75

D FOLLOW-UP POSTCARD . . . . . . . . . . . . . 76 


\section{LIST OF TABLES}

TABLE

Page

I Methodologies Used in Carryover and Their

Perceived Effectiveness . . . . . . . . . .

II Use of Outside Individuals in Management and

Their Perceived Effectiveness . . . . . . . . .

III Use of Materials and/or Equipment in Management and Their Perceived Effectiveness . . . . . . . . . 24

IV Management Practices . . . . . . . . . . . . 
LIST OF FIGURES

1. Percentage of clinicians who include a given

technique in management . . . . . . . . . . .

2. Effectiveness of management techniques in promoting carryover . . . . . . . . . . . .

3. Methods included in the proposed carryover hierarchy and their percentage of use . . . . . .

4. Percentage of clinicians who include a given individual in management . . . . . . . . . .

5. Perceived effectiveness of outside individuals in management to promote carryover . . . . . . . .

6. Percentage of clinicians who include given materials or equipment in management . . . . . .

7. Reported effectiveness of materials and/or equipment used in management to promote carryover . . . . . .

8. Reported months of management needed until the client uses the target sound in conversational speech in the clinic room . . . . . . . . . .

9. Reported months of management needed until the client uses the target sound in conversational speech outside the clinic room . . . . . . . .

10. Percentage of articulation management program devoted to carryover, as reported by 125 clinicians 


\section{CHAPTER I}

\section{INTRODUCTION AND PURPOSE}

\section{Introduction}

Speech-language clinicians have traditionally used five skill acquisition steps in articulation remediation. These include: 1) auditory discrimination; 2) sound production in isolation; 3) sound production in words; 4) sound production in phrases and sentences; and, 5) sound production in conversational speech (Berry and Eisenson, 1956; Johnson, Brown, Curtis, Edney and Keaster, 1967; and Van Riper, 1978). Speech-language clinicians may have assumed when they have followed these steps and taught a new behavior to a student, the student subsequently will utilize that new skill in situations outside the teaching setting. If some degree of generalization to novel situations does not occur, the clinician is forced to teach the client each misproduced phoneme in every possible situation in which it might occur. On the other hand, since correct production of the sound in novel situations is the goal of management, any methods of promoting that generalization likely would benefit the client.

Traditional management procedures facilitate the acquisition of articulatory skills through the stages of sound production in phrases and sentences. Generalization of learned skills to novel situations outside the clinical setting, often described as "carryover," is a phase of management often taken for granted. The process by which 
"carryover" occurs is a little studied area in terms of articulation learning. Most speech-language clinicians recognize their responsibilities extend beyond the clinical setting to the outside environment and, although suggestions for methods of facilitating carryover are often cited in the 1iterature (Johnson et al., 1967; Enge1, Brandriet, Erickson, Gronhovd and Gunderson, 1966; Wing and Heimgartner, 1973; and Winitz, 1975), little is known about the variables which are critical to the carryover process.

Twenty years ago the majority of cases seen in public school settings involved articulation management (Chapman, Herbert, Avery and Selmar, 1961). Even though the proportion of articulation cases appears to be decreasing (Neal, 1976), the goal of these programs remains the carryover of newly learned articulatory skills to settings outside the clinical environment. Clinicians report that carryover in articulation management is one of the most difficult and time-consuming problems they face (Johnson, 1972). The literature offers little data to assist the clinician in determining what methods should be used and which are effective in facilitating carryover.

\section{Statement of Purpose}

This investigation was designed to determine the nature of methodologies utilized by public school clinicians in Oregon to facilitate carryover with clients originally diagnosed as having articulation disorders.

An essential question of this study was: What methodologies do clinicians utilize to promote carryover with their articulation disordered clients? 
An additional question was: How effective are the methodologies used perceived to be?

\section{Definition of Terms}

For the purposes of this study, the following operational definitions will be utilized.

Carryover: The transfer of acquired skills to situations outside the clinical setting.

Creative dramatics: Stories, plays, poems or skits used in management to provide structured and/or unstructured speaking situations in which the client can use his/her target sound(s).

Stimulus generalization: The phenomenon whereby an individual makes a response that has been elicited by a particular stimulus in the presence of a new stimulus (Mowrer, 1977). For example, the child is first taught to produce the target sound correctly in the presence of the clinician and then to generalize this skill to other speaking situations outside the clinical setting.

Response generalization: This occurs when one stimulus evokes several different responses. For example, the child learns to produce the target phoneme in syllables, and then generalizes this skill to words, phrases and sentences in response to a given stimulus. 
CHAPTER II

REVIEW OF THE LITERATURE

\section{Carryover}

Twenty years ago articulation disorders composed the majority of the public school speech clinician's caseload (Chapman et al., 1961). More recent survey data (DesRoches, 1976; Neal, 1976; and Van Hattum, 1976) show a growing awareness of language and an increased number of language cases being served. Clinicians no longer have the time they once did to spend with their articulation disordered clients; and yet, the ultimate goal of management remains the same. That goal is "carryover," the generalization of learned skills to novel situations outside the clinical setting. Articulation management clients who have achieved carryover are able to use their target sound in conversational speech in response to a variety of stimuli outside the clinical setting (Carrier, 1970; Mowrer, 1971; Wing and Heimgartner, 1973; and Coste110 and Bosler, 1976).

Some clinicians view carryover as a separate and final step in articulation management (Wing and Heimgartner, 1973). With this approach, the child must be able to produce the target sound in conversational speech before any techniques to help that child use his new skill in novel situations are incorporated into management sessions. Other clinicians view carryover as an ongoing process by including carryover techniques in all phases of management. A given methodology for 
facilitating carryover may apply equally well to either of these philosophies. For example, one technique suggested as effective in promoting carryover is having the child work with the classroom teacher (Engel et al., 1966). Clinicians who view carryover as a final step would have the teacher evaluate or monitor the child's speech at the conversational level only. Clinicians who promote carryover throughout their management program, on the other hand, would have the teacher evaluate or monitor the child's speech at each stage of management.

All steps of articulation intervention programs with the exception of carryover have been organized, defined and supported by extensive research (Wing and Heimgartner, 1973). Efforts in a management program are futile if articulatory errors continue to occur in conversational speech away from the clinic (Winitz, 1975). Unfortunately, few studies have looked specifically at the carryover process or have compared any of the methods or techniques suggested in the literature. Suggestions or ideas for carryover techniques, however, are abundant in the literature.

\section{Methods for Facilitating Carryover}

Two approaches to carryover have been suggested by the literature. One is to provide some speech training in the clinic setting followed by structured speaking situations where the child is prompted to articulate the target sound correctly in a variety of speaking environments while in the presence of his teachers, peers and parents (Lillywhite, 1948; Marquardt, 1959; Engel et al., 1966; Carrier, 1970; Mowrer, 1971; Fudala, 1973; and Wing and Heimgartner, 1973). This procedure might best be described as planned extraclinical stimulus 
generalization.

The other approach is to provide all of the necessary speech training within the speech room so that positive transfer of the taught sound occurs without manipulation of stimuli outside the clinic room. This technique involves specially selected practice materials and structuring of the management procedures within the clinic room (Sutton, 1955; Powers, 1957; Engel et al., 1966; Brookshire, 1967; McReynolds, 1970; and Van Riper, 1978). Either of these strategies for accomplishing carryover may be valid but neither has clearly emerged as the approach of choice.

Individuals in the Child's Environment

Clinicians may enlist the help of teachers, parents, peers, siblings or other individuals in the child's immediate environment to aid in management. The child's use of the target sound in structured situations with individuals other than the clinician is believed to be beneficial in promoting carryover. Clinicians, however, who enlist help from individuals in the client's environment frequently are limited by the availability, willingness or ability of those persons to participate in the program. When the cooperation of outside individuals is secured, their help appears to aid in the carryover process (Marquardt, 1959; Carrier, 1970; Carpenter and Augustine, 1973; Fudala, 1973; and Wing and Heimgartner, 1973).

Most textbooks concerning speech intervention mention the teacher's role in helping the child use the target sound in classroom speaking situations. Mowrer (1971) evaluated classroom teacher effectiveness in a speech correction program in which the teachers were involved 
with actual management procedures designed to teach "lisping" children to say /s/ correctly in a variety of speaking situations. The program required that teachers spend about ten minutes daily teaching correct /s/ production to a "lisping" child. The experiment is reported to have placed impractical demands upon the teachers and, due to inconsistencies in the deliveries, the value of the program could not be measured. Several speech clinicians have suggested that peers can help the child use new sounds correctly when reading or speaking in the classroom or on the playground (Marquardt, 1959; and Engel et a1., 1966). Marquardt (1959) based her "speech pals" program on the theory that children learn behaviors more quickly from their peers than from adults. Children with acceptable speech are called "speech pals" and help with the carryover process by providing speech stimulation outside of the clinical setting. In this program a leader-type child, selected by the classroom teacher, accompanies the speech handicapped child to the management session once a week. After an adequate number of sessions, where the helper observes the clinician's techniques and attitudes, the speech pal then spends fifteen minutes a day helping the child practice what he has learned in speech class. The primary role of the speech pal is that of moral support, so the speech handicapped child is not made to feel "different" because he comes to speech (Marquardt, 1959).

Engel et al. (1966) has suggested a "carryover friend," similar to Marquardt's "speech pal," could be seated near the child who needs speech monitoring. At specific times during the day the friend could depress a clicker to signal correct sound production. The number of clicks could be totaled at the end of the day and used as points for a class party. Research has not been done on this method to demonstrate 
its effectiveness.

In addition to aid from teachers and peers, parents can help facilitate carryover. Sometimes, they work directly with the child on his assignments. Even if they are unable to work with the child, their interest in what he/she is working on and how the child is doing may reinforce efforts to improve. Parents, and specifically mothers, have been advocated as aides in the carryover process by numerous authors (Lillywhite, 1948; Tufts and Holliday, 1959; Sommers, Furlong, Rhodes, Fichter, Bowser, Copetas and Saunders, 1964; Engel et al., 1966; Carrier, 1970; Mowrer, 1971; and Wing and Heimgartner, 1973).

Many parents need specific instructions about how to respond to their child's speech. Some parents correct their child's speech so frequently that he/she becomes either insensitive or hypersensitive to reactions at home (Engel et a1., 1966). However, if guidelines for parental involvement are provided a home program may expand the management program beyond the clinic room, a concept viewed as an important dimension of articulation carryover by Van Riper (1978). Home programs completed by parents may be a means of attaining carryover without extended clinical management (Wing and Heimgartner, 1973). Carrier (1970) utilized parental help in a novel manner by specially training mothers to carry out a home program of articulation management prior to any clinical intervention. He found this method reduced the manpower needed to complete an average articulation management program and may have had the additional benefit of promoting carryover.

Sommers (1962) looked at the effectiveness of training mothers of children with functional misarticulations. Mothers were involved in the management stage rather than specifically in carryover. Groups of 
subjects whose mothers were trained made significantly greater progress in improving articulation skills than subjects whose mothers were not trained. If mothers trained in management were able to improve the articulatory skills of their children, then it would seem logical to assume that mothers trained in carryover techniques would increase the amount of stimulus generalization of the target sound made by their children. A similar study on the effects of maternal attitudes on improvement in articulation management found that children of mothers trained to assist in speech correction improved significantly compared with children of mothers not trained (Sommers et a1., 1964). The children were tested two months post-management so it appears some degree of carryover was measured.

Parent education programs may help parents who are assisting their articulation disordered children with speech intervention. Researchers have suggested that if parents had pertinent facts about speech disorders and could eliminate their anxiety and guilt feelings, those parents then could help their children with their speech (McIntyre and McWilliams, 1959; McWilliams, 1959; and Webster, 1966). If parents also are educated about the process of articulation acquisition, they may be better able to follow the progress their children make and formulate more realistic expectations of their children's speech .

\section{Management Techniques}

Not all clinicians involve the client's associates as a means of promoting carryover. Another philosophy of carryover methodology relies on a variety of management techniques to be used in the clinical 
setting (Sutton, 1955; Powers, 1977; Engel et al., 1966; Brookshire, 1967; McReynolds, 1970; and Van Riper, 1978).

One method of promoting carryover is for the child to produce habituated sounds in as many different contexts as possible, in varied social and emotional settings. One means of achieving this goal without leaving the clinic room is through creative dramatics. This method is a means of practicing newly learned phonemes in natural language situations (Bush, 1978). Creative dramatics can reduce tension and promote enjoyment and ease of speaking because the clients learn to feel free to talk without embarrassment in this medium (McIntyre and McWilliams, 1959; Hayes, 1976; and Via, 1976).

Sutton (1955) believes one of the most practical and rewarding methods of reinforcing a pupil's progress is that of integrating speech management with the student's language arts program. The advantages of this approach are that it: 1) affords a vehicle by which the principles of speech correction can be applied; 2) provides a link between classroom material and speech management material; 3 ) provides an opportunity for the child to assume added responsibility and initiative in the carryover of speech management outside the speech room; and, 4) establishes criteria for judging the stability and effectiveness of techniques and materials involving the academic, social and emotional status of the child (Sutton, 1955). Speech correction does not occur in a vacuum, and the more frequently the management program is tied to the daily classwork of the child, the better the prognosis for successful carryover (Sutton, 1955).

Mowrer (1971) and Brookshire (1967) advocate following a structured behavior modification program to promote carryover. These 
behavior modification programs are based on the principles of operant conditioning, the process whereby consequences or consequent events occur relative to a response so that the response is controlled. The result of operant conditioning is an increment or a decrement in the rate of the responses, subject to the contingencies. When applying operant conditioning techniques to the speech patterns of a client, the desired behavior of correct phoneme production should increase as a consequence of the management program. The nature of the management program itself is said to facilitate carryover due to specific programming of all components including planned reinforcement schedules and gradual altering of behavior toward the desired goal of correct articulation.

One must not forget the client himself in the rush to devise means of stimulating carryover. Many clients approach management passively as if they needed only to make an appearance. They sit down and wait for the clinician to do something for or to them. Some clinicians respond to this attitude by assuming all responsibility for changing the client's behavior without placing responsibility with the client. The client should understand that management is a procedure by which he changes his own behavior with the clinician's help. Responsibility for change is placed with the client and redefined as often as needed. A sense of client responsibility can be strengthened through client devised homework assignments (Engel et a1., 1966; and Castee1, 1979). The client's desire to improve his speech is a powerful force in obtaining carryover. This desire should be encouraged and developed as soon as management begins.

Awareness of his speech is one way for the client to develop a 
desire to change. This awareness may be acquired through auditory training exercises. The client must not only learn to discriminate between his responses and those of the clinician, but also must realize the differences he perceives constitute a real or potential problem. It is only then that he can accept responsibility for his speech.

\section{Materials and/or Equipment}

Commercial carryover programs may include operant conditioning principles in their format. Gerber's (1973) program for habituating correct articulation patterns required that the client produce nonsense syllables and words in all of the combinations and conditions of rapid connected speech at several levels of difficulty. Because of the strong bond between meaning and the habitual pattern of the error sound, Gerber (1973) does not introduce meaningful units of speech until normal production and self-monitoring have been achieved at each level.

Other materials said to facilitate carryover are games (Van Riper and Irwin, 1958). Games may be a valuable means of creating excitement, absorbing attention, and facilitating less deliberate careful dril1-1ike speaking situations (Engel et a1., 1966). Games are also an effective means of involving family members and friends in the management process by having them play the games with the client.

Some clinicians may choose to facilitate carryover by involving the child's associates outside the clinic to monitor his speech. Others may choose to use specially designed programs or methods without leaving the clinic room. Others still may choose to use a combination of these practices. No matter which philosophy is adopted, several important principles of positive transfer of training influence the 
success of the procedures.

\section{Transfer of Training}

Basically, four major factors have been found to influence positive transfer of training or carryover. They are: 1) stimulus similarity, 2) amount of training, 3) reinforcement variability and 4) punishment (Mowrer, 1977). The more similar the stimuli in the training and test activities, the greater the positive transfer, if the response remains constant (0sgood, 1949). The child is more likely to generalize learned skills to situations outside the clinic room if these environments are similar to clinical activities. A second factor, the amount of training, also alters the degree of transfer. The more training provided on the original task the greater the positive transfer, up to a certain point beyond which positive transfer either ceases or in some cases begins to decrease (Mowrer, 1971). Children with disordered articulation who are continually reminded they say certain sounds wrong are more likely to withdraw and show no improvement as a result of the comments. It is currently not known how much training is required to achieve carryover at given stages of speech acquisition. The third factor influencing transfer of training is the reinforcement schedule. When correct responses are reinforced immediately, the likelihood of positive transfer is greater than if those responses are not reinforced (Mowrer, 1971). Furthermore, responses acquired under conditions of intermittent reward are more likely to transfer positively than are those acquired under conditions of constant reward (Mowrer, 1971). For example, when a rich reinforcement schedule is suddenly withdrawn, as when a child leaves the clinic room, the 
child's behavior extinguishes much more rapidly than when the reinforcement schedule is leaner. Punishment, the fourth variable which influences carryover, may lead to a greater degree of transfer of training. A tendency to respond increases when a desired behavior is reinforced. A tendency not to respond with an undesirable response increases when the undesirable response is punished (Mowrer, 1971). If the child is producing the target sound incorrectly, the use of punishment may result in an increase of correct sound production through a decrease in incorrect sound production. Many clinicians are unsure of what action to take following a child's incorrect response. The data regarding the influence of punishment are insufficient to support any conclusions.

There has been, to date, a lack of information dealing with clinical practices currently used in the public schools to promote carryover. The literature suggests a variety of methods clinicians in the public schools might use but there are few data on what clinicians actually use; nor, are there data showing which of the methods they consider to be effective in promoting carryover. 
CHAPTER III

METHODS AND PROCEDURES

Methods

\section{Subjects}

Subjects for this survey included 126 public school speechlanguage clinicians in Oregon.

Criteria for participation in the study were:

1. Listing in the 1979 American Speech, Language and Hearing Association (ASHA) and/or Oregon Speech and Hearing Association (OSHA) directories,

2. A public school caseload including clients with disordered articulation skills, and

3. More than nine months' experience in a public school setting as a speech-language pathologist.

of the 125 clinicians who reported their level of training, 112 (90 per cent) held a master's degree, 9 (7 per cent) have completed a fifth year of training and 4 ( 3 per cent) held a bachelor's degree. Al1 of the clinicians reported speech pathology as their area of training. The average length of time that the clinicians have worked in the public schools is 8.3 years with a range of 1 year to 28 years. Their average caseload size was 45 students per week and they served an average of 3.5 schools (Appendix A).

\section{Instrumentation}

A questionnaire (Appendix B) was designed by this examiner to yield information about carryover practices of public school clinicians. 
Information on the construction of the questionnaire was drawn from Moser and Kalton (1971) and Dillman (1978). Material in the questionnaire was based on a review of the literature dealing with techniques for facilitating carryover in speech/language programs.

Five categories of data composed the questionnaire: demographic data, management practices, use of carryover methodologies, effectiveness of carryover methodologies and related information. The first category, demographic data, consisted of seven open ended questions designed to provide information germane to the description of clinicians responding to the questionnaire. These questions were not numbered.

The second category, management practices, consisted of questions one, six and seven designed to elicit information relative to schedules and emphasis of client contact. The format of question one was forced choice and that of questions six and seven was open ended.

The third category, use of carryover methodologies, consisted of the forced choice portions of questions two, three and four. Each question evaluated one aspect of clinical methodologies. Question two, dealing with carryover techniques, was composed of twelve forced choice items followed by three open ended items. Question three, dealing with people included in carryover, was composed of six forced choice items and two open ended items. Question four, materials and/or equipment used in carryover, was composed of four forced choice items and three open ended items.

The fourth category, effectiveness of carryover methodologies, consisted of the rank order portions of questions two, three and four. Again, each of these questions evaluated one aspect of this category. 
Question two, dealing with carryover techniques, asked that clinicians rank order only those items they reported using in carryover. They were asked to assign the most effective methodology in a given category a value of "one," the second most effective method a "two" and so on until all the methods used were assigned a rank value.

Questions three and four followed the same procedures as question two. The only difference between the questions was that question three dealt with individuals included in the carryover program and question four requested data on the effectiveness of materials and equipment used.

A fifth category, related information, included questions five, eight and nine. Question five contained thirteen forced choice items followed by four open ended items requesting data as to what the clinician would add to a carryover program. Questions eight and nine were open ended in nature. Question eight asked the clinician to list major problems in attaining carryover and question nine requested any additional information the clinicians wished to report.

A pilot study completed by ten speech-language pathologists working in the public school system in Corona, California, provided comments which were the basis for changes in the questionnaire format.

\section{Procedures}

A questionnaire (Appendix B), a letter of introduction and consent (Appendix C) and a stamped, addressed return envelope were mailed to two hundred speech-language pathologists listed in the ASHA or OSHA directories as working in the public schools. Follow-up postcards (Appendix D) were sent to all clinicians two weeks after the initial 
mailing. The postcard served as a reminder to complete and return the questionnaire for those clinicians who had not done so and a thank-you to those who had. Clinicians read and responded to items listed on the questionnaire per instructions included in each question (Appendix B).

\section{Data Coding}

Data were transferred from the surveys to grid sheets and recorded according to item and questionnaire number. Data not related to a specific questionnaire item, such as "other" methodologies used, were recorded according to question and questionnaire numbers. Responses to questions eight and nine, problems and additional information, were recorded on index cards according to survey number, the responses from one questionnaire per card.

Analysis of the Data

Demographic Data. Demographic data were analyzed by descriptive statistics with the mean value and the range being reported.

Management Practices. Management practices, questions one, six and seven of the questionnaire, were analyzed in terms of descriptive statistics. The median value of question one, the percentage of management devoted to facilitating carryover, was reported. The data from questions six and seven were reported in mean values.

Use of Carryover Methodologies. Responses to each item were totaled, then converted to percentages and reported as percentage of clinicians utilizing a given methodology in their management programs.

Perceived Effectiveness of the Carryover Methodologies. In that

1) respondents only ranked those items they identified as using and

2) some items were used much more frequently than others, the rank 
totals per item on "effectiveness" were based on unequal numbers of respondents, thereby making comparisons of those totals meaningless. In consultation with Grove (1980), the following formula was developed to provide a basis for comparing the total rank values across items. That conversion formula is:

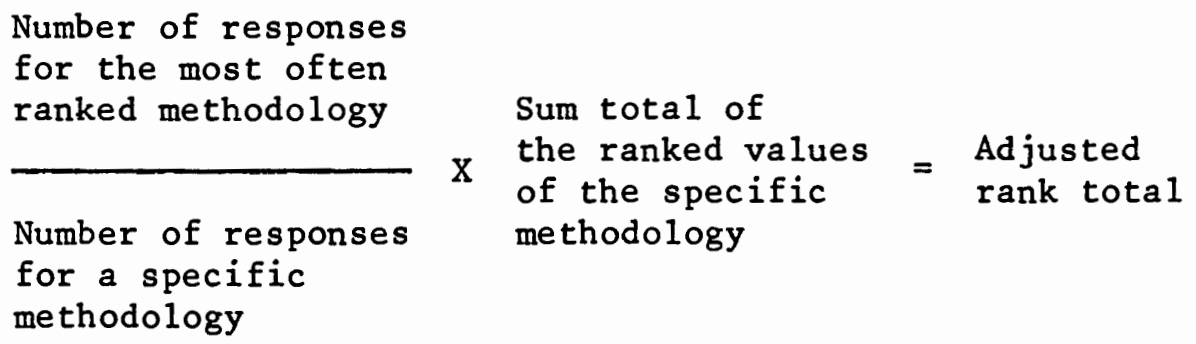

This formula was applied to estimate the value of rank totals if all items had been included in the ranking as frequently as the most frequently ranked item. That is, the size of the ranks given a particular item were used to estimate the values of the missing rank data for that item. In this way, without penalizing a given item for lack of frequent use, relative effectiveness among the items could be estimated. However, it should be cautioned that inferences based on comparisons between total item ranks in this way would be more credible for items with less missing data than with more missing data.

Respondents ranked methodologies reported in the open ended portion of the questions, "other" methodologies used but not listed as a question item. The rank values were adjusted to exclude these items prior to transfer of data from the questionnaire to grid sheets. The resulting data reported the rank order of only the forced choice items used by the clinicians. 
CHAPTER IV

RESULTS AND DISCUSSION

\section{$\underline{\text { Results }}$}

One hundred and fifty-nine of the two hundred questionnaires ( 80 per cent) were returned. One hundred and twenty-six were used in the final tabulation of results; thirty-three were excluded for a variety of reasons; such as the respondent no longer held a clinical position, did not have a caseload including articulation disordered clients, or the survey was returned more than two months after the initial mailing.

The purpose of this study was to investigate the carryover practices of speech-language clinicians in Oregon's public schools.' An essential question was: What methodologies they use to promote carryover for their clients with disordered articulation. An additional question was: How effective are the methodologies used perceived to be?

\section{Methodologies Used}

Management Techniques. Examination of the survey data revealed the percentage of clinicians who use the following methods: client self-evaluation ( 83 per cent); client completion of homework assignments ( 81 per cent); client works with individuals other than the clinician (79 per cent); client practices until the responses are automatic ( 71 per cent); client works with the clinician outside the clinic room (63 per cent); distribute reminders in the client's environment 
(62 per cent); follow a structured behavior modification program (50 per cent); use auditory discrimination training (50 per cent); include creative dramatics in management ( 46 per cent); integrate management with the language arts program (29 per cent); client develops his own homework assignments (21 per cent); and, client practices under emotional conditions (12 per cent) ( Table I).

Individuals in the Child's Environment. The data also revealed the percentage of clinicians who include non-clinician individuals in management activities: client's parents ( 94 per cent); classroom teacher ( 94 per cent); client's peers (60 per cent); speech pals (50 per cent); classroom aides ( 34 per cent); and, speech aides ( 16 per cent) (Table II).

Materials and/or Equipment. Data revealed the percentage of clinicians including the following materials or equipment in their program: clinician developed carryover programs (82 per cent); tape recorders (54 per cent); workbooks (53 per cent); and, commercial carryover programs (52 per cent) (Table III).

\section{Effectiveness of Reported Methodologies}

Management Techniques. Comparison of adjusted rank totals revealed the relative effectiveness of the methodologies as perceived by the clinicians. The methods used were ranked as follows with "1" representing the most effective method used: client self-evaluation (1); client practices until responses are automatic (2); follow a structured behavior modification program (3); client works with individuals other than the clinician (4); client works with the clinician outside the clinic room (5); use auditory discrimination training (6); 


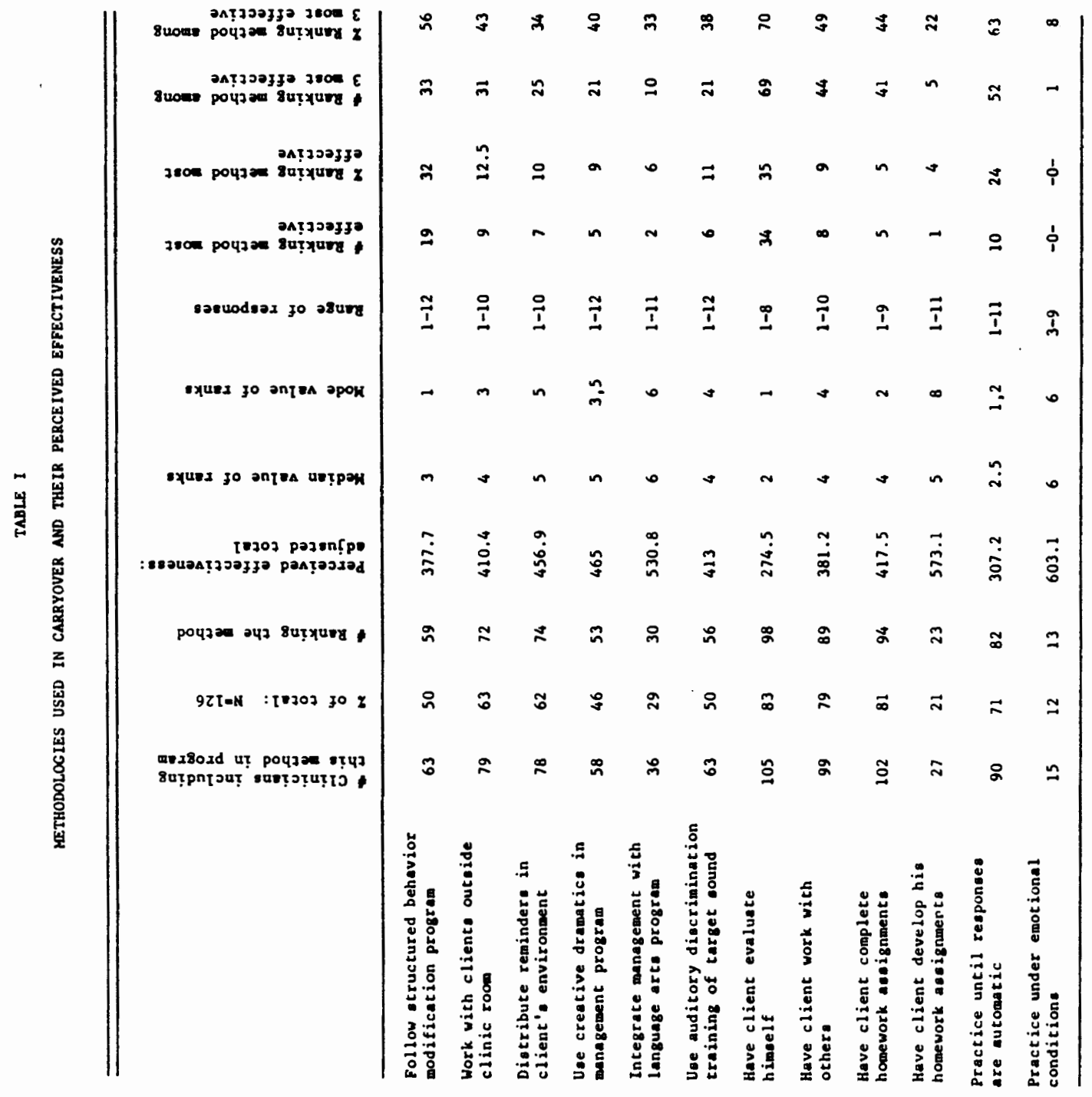




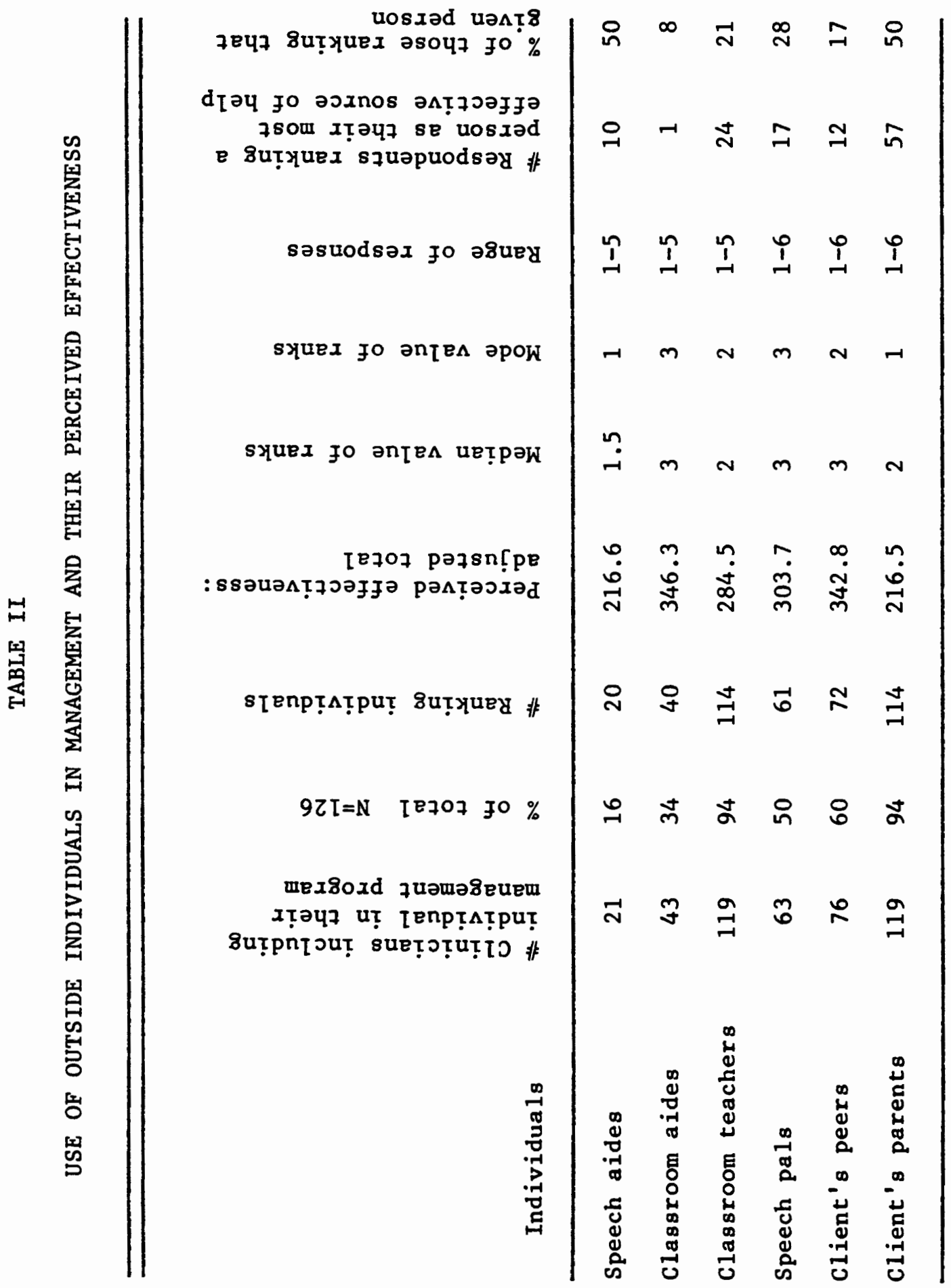




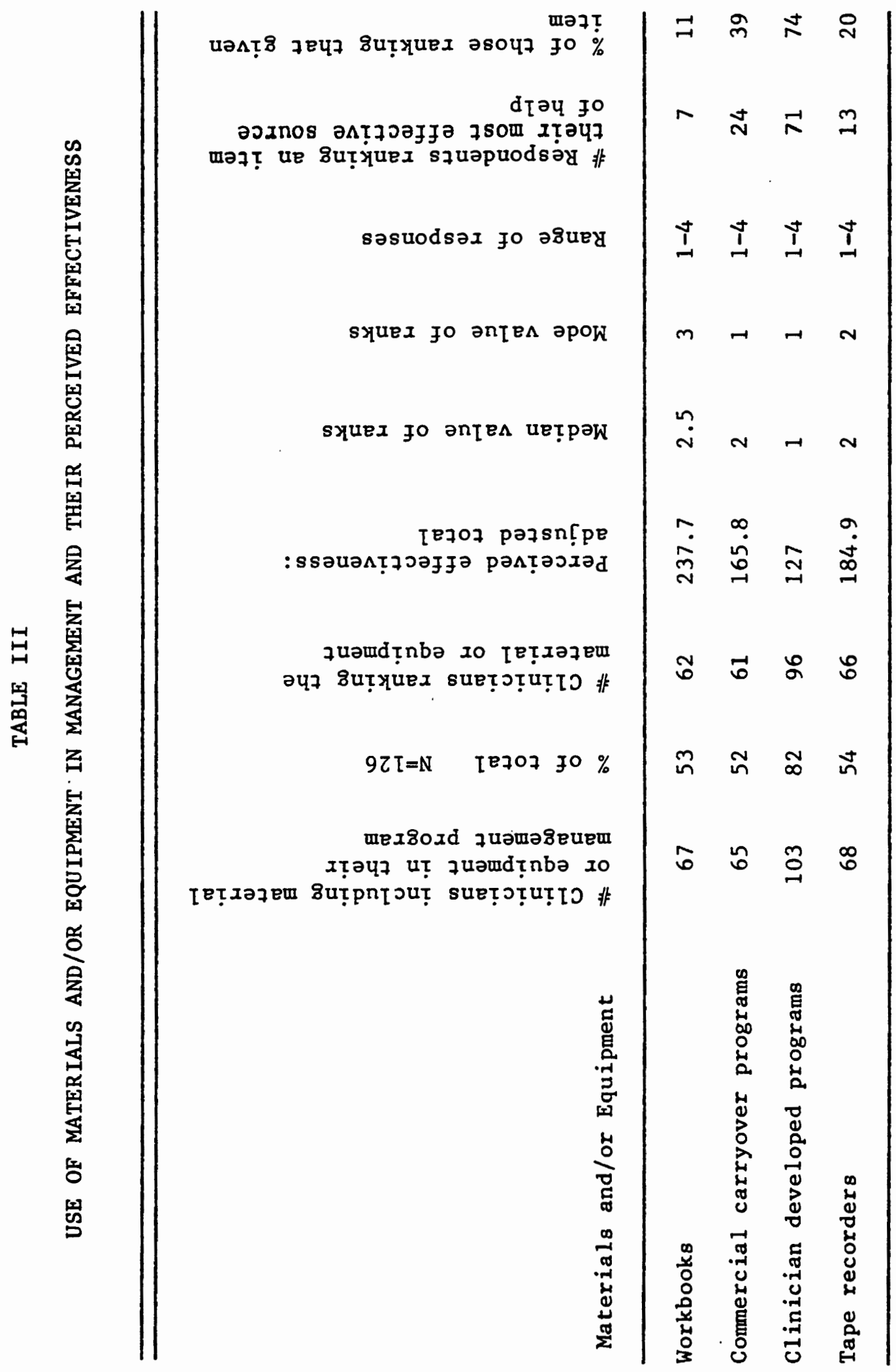


client completion of homework assignments (7); distribute reminders in the client's environment (8); include creative dramatics in management (9); integrate management with the language arts program (10); client develops his own homework assignments (11); and, client practices under emotional conditions (12) Table I).

Individuals in the Client's Environment. The effectiveness of individuals other than the clinician was also evaluated. The effectiveness of non-clinician individuals was rank ordered as follows: client's parents (1); speech aides (2); classroom teachers (3); speech pals (4); client's peers (5); and, classroom aides (6) (Table II).

Materials and/or Equipment. The materials and/or equipment used were ranked as follows: clinician developed carryover programs (1); commercial carryover programs (2); tape recorders (3); and, workbooks (4) (Table III).

\section{Management Practices}

The average clinician surveyed schedules clients for articulation management 2.5 times per week for a total of fifty minutes per week. An average of thirteen weeks of management are needed before the client produces the target sound in the clinic setting. Twenty-four and a half weeks, on the average, are spent in management to generalize the sound to settings outside the clinic room (Table IV) with approximately 20 per cent of the management program devoted to carryover.

\section{Discussion}

The purpose of this study was to augment existing knowledge of clinical management practices. Specifically, surveys were used to 
TABLE IV

MANAGEMENT PRACTICES

\#. Clinicians

reporting

data

Mean value

Range

of data

of data

Number of times clinician

sees client per week

122

2.3 sessions

$1-4$ sessions

Length of each session

122

25 minutes

5-30 minutes

Amount of time per week each client is seen

50 minutes

20-120 minutes

Weeks of management needed

until client uses target

sound in speech room

105

13 weeks

1-34 weeks

Weeks of management needed

until client uses target

sound outside speech room

90

24.5 weeks

5-72 weeks

determine what methodologies are being used by public school clinicians in Oregon to promote carryover with articulation disordered clients. A secondary question dealt with the perceived effectiveness of these methods. Clinicians also provided data on clinical management practices and problems encountered with carryover programs.

\section{Demographic Data}

The first question of the survey, asking the number of students in the school system, was designed to yield the size of the population from which clinicians drew their caseloads. Wording of this item was such that the resulting data was inconclusive. Sixty-five per cent of the respondents answered this question, reporting that the average 
number of students in the school system was 10,000 . The range of responses was from 20 to 53,000 . A more meaningful question may have been to ask the clinicians "the number of students from which you draw your caseload."

Ninety-eight per cent of the respondents answered the question regarding caseload size. They reported serving an average of $45 \mathrm{stu}-$ dents per week with the responses ranging from 12 students per week to 150 students (Appendix A). In the past, speech-language clinicians have managed large numbers of cases, as reported by Steer (1961) who found the mean caseload of 1462 clinicians to be 130 students. Johnson (1972) reported the average caseload size of North Dakota clinicians to be 58 students per year. Four years later DeRoches (1976) surveyed clinicians in a suburban Maryland school system. The average caseload of these clinicians was 80 students per week. Neal (1976) found similar results in a national survey of speech-language clinicians in secondary schools whose average caseload was 72.68 students per week. The trend appears to be toward smaller caseloads but the size may vary from region to region. Two questions not asked in the questionnaire but which may influence caseload sizes are: 1) Is the clinician employed on a part-time or full-time basis; and 2) does the clinician have an aide who handles part of the caseload? A sample with a significant number of part-time clinicians may decrease the average number of students seen per week. Conversely, a sample with a large number of aides serving clients may increase the average number of students served per week.

Ninety-eight per cent of the clinicians reported the number of schools they served. Data ranged from one school to 11 schools served 
by a given clinician with the average being 3.5 schools (Appendix A). Neal (1976) found a slightly lower average of 2.89 schools served per clinician in his national survey of clinical practices.

\section{Methodologies and Their Effectiveness}

Clinical practices in articulation management can be grouped in several ways, one being to separate those methods used within the clinical setting from those that occur outside the speech room. This grouping is arbitrary in that many techniques frequently associated with one setting may be used equally well in another. For example, creative dramatics is a technique designed to simulate a variety of speaking situations without leaving the speech room. Creative dramatics also may take the form of skits, plays or poems performed for the student's classmates.

\section{Methods Used in the Clinic}

Twelve clinical methodologies were listed on the questionnaire with spaces provided for clinicians to note additional methods. Of the twelve methods, the following six are techniques frequently used within the confines of the clinic room: self-evaluation, auditory discrimination training, automatization of responses, creative dramatics, practicing under emotional conditions and behavior modification.

Auditory Discrimination Training. Auditory discrimination training was used by 50 per cent of the respondents making it the seventh most used method (Figure 1). In terms of effectiveness, clinicians ranked auditory discrimination training as the sixth most effective technique (Figure 2). Auditory discrimination exercises may teach the 

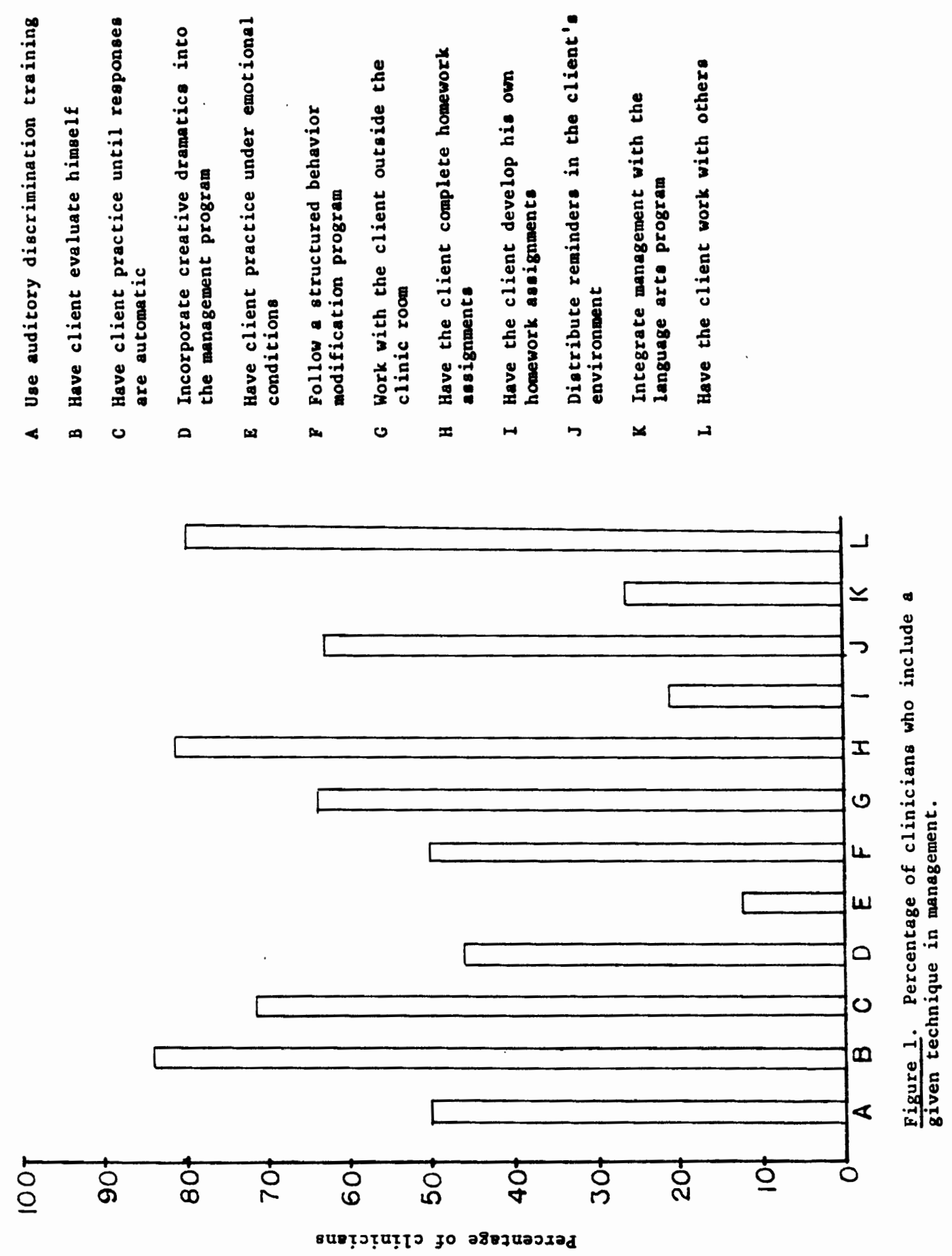

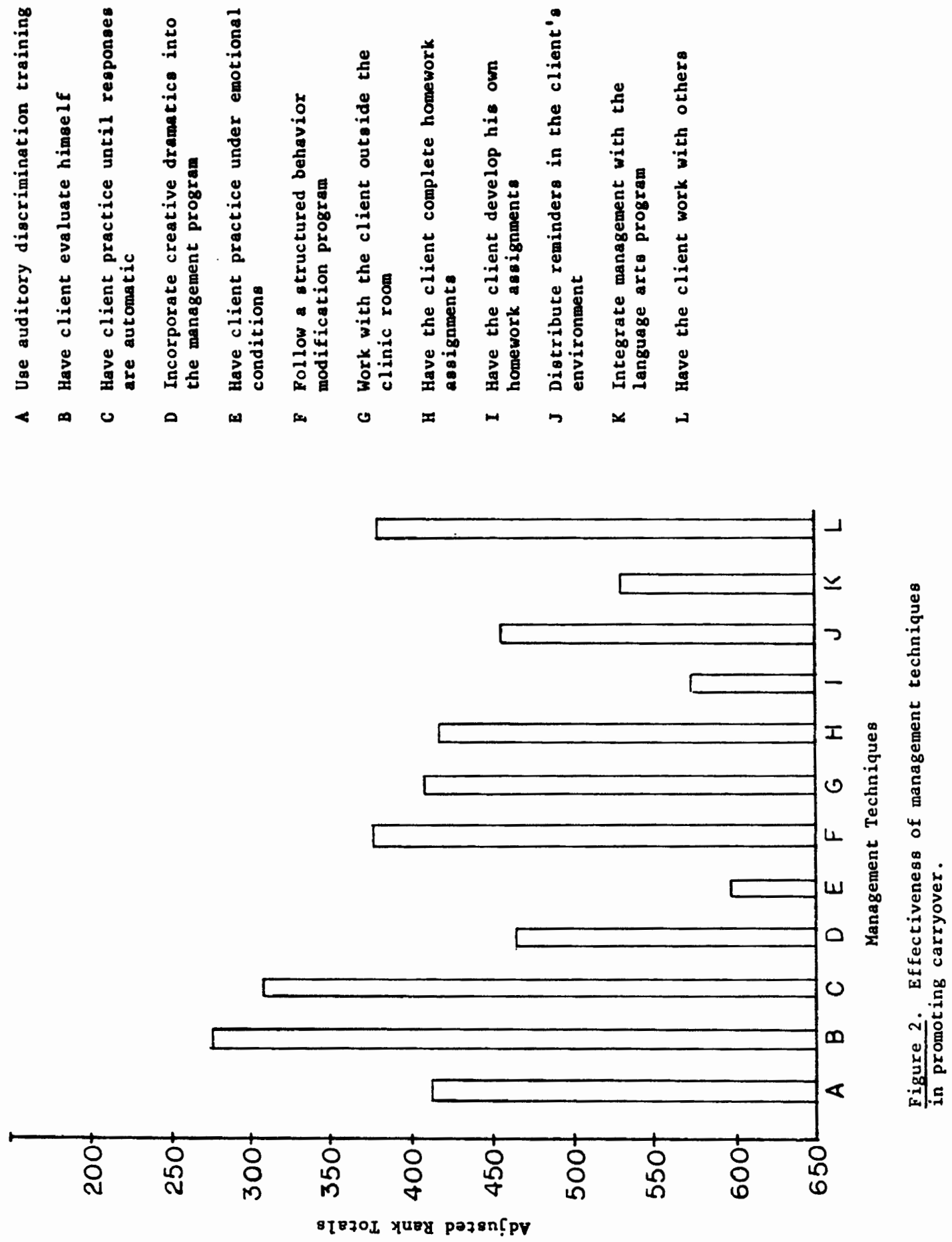
client not only to discriminate between his responses and those of the clinician, but more importantly for carryover, to discriminate between his correct and incorrect responses. In order for carryover to be effective, the client should monitor his speech for correctness of production in a variety of situations. If he cannot monitor his speech and, hence, is unable to evaluate his productions, it follows that he will not know if he is using the target sound correctly. He could return to old and familiar speech habits yet be unaware that he is doing so.

One would assume that good auditory discrimination skills would form the foundation of any articulation management program, yet 50 per cent of the respondents did not report including this step in their programs. In addition, those who did report using auditory discrimination techniques believed them to be only moderately effective in promoting carryover. Programs which do not include adequate auditory training skills for the client to learn to monitor his speech may be one reason why the management program fails at a later stage. Even though tactile and kinesthetic training was not included as part of the survey, it may be that these senses would be helpful in the acquisition of articulation skills.

Client Self-evaluation. Client self-evaluation was considered the most popular and effective strategy used by the clinicians (Figures 1 and 2). Eighty-three per cent of the respondents reported using self-evaluation with their clients. As with auditory discrimination skills, the client should evaluate the correctness of his production in order to monitor his speech in a variety of environments. Again, if he is not able to evaluate his own speech, he may not be able to continue 
to use his target sound correctly over time. Client self-evaluation presupposes auditory discrimination skills on the part of the client. Because client self-evaluation was believed to be very effective, but auditory discrimination training was only moderately effective, many clients may be starting the program with adequate skills for selfevaluation. Those who do not have adequate auditory, tactile or kinesthetic skills may need more extensive management in this area than the clinician provides.

Practice Until Responses Are Automatic. Seventy-one per cent of the clinicians reported that they have the client practice until responses are automatic, making it the fourth most often used technique (Figure 1). Those who use this method consider it the second most effective technique used (Figure 2). A similar study conducted in 1970 with North Dakota clinicians found skill automatization to be the second most frequently used technique even though only 27 per cent of the respondents reported using automatization in management (Johnson, 1972). One reason this method is not more frequently used, even though it is felt to be effective for those who use it, may be a time factor. Some clinicians consider their clients "underserved" and that more time is needed for management at the carryover level. Unfortunately, automatization takes time.

Creative Dramatics. Even though creative dramatics is widely discussed in the 1iterature (McIntyre and McWilliams, 1959; Hayes, 1976; Via, 1976; and Bush, 1978), less than half of the clinicians, 46 per cent, use this method with their articulation disordered clients (Figure 1). Those who do use the method do not list it among their most effective practices for carryover (Figure 2). One possible reason 
for these results may be that the respondents may be operating under a different definition of "creative dramatics" so in actuality may be using this method but not reporting its use.

Creative dramatics is a technique designed to give the client the opportunity to practice the target sound in a variety of situations. This questionnaire used the term "creative dramatics" loosely by including in the category prepared material such as plays, poems and stories. Several problems may influence the usefulness of creative dramatics as a management technique. One problem may be that the client must be at the conversational level of production before he/she is to use the target sound in structured or unstructured speaking situations. Creative dramatics, therefore, is not a technique which can be integrated into all stages of management. Another problem may be that unstructured tasks require greater amounts of time to elicit a given number of responses. A third problem may be lack of time available for the clinician to plan the spontaneous events. A final consideration is pressure to dismiss clients who are at the conversational level because of extensive caseloads and administrative pressure to serve more clients. Practice under Emotional Conditions. Using new responses under emotional conditions, a technique advocated by Van Riper and Irwin (1966), was used by only 12 per cent of the respondents to this survey (Figure 1). As a result, this technique was the least often used of the twelve methodologies listed on the questionnaire. The clinicians also ranked it as the least effective technique (Figure 2). This contradicts the Johnson (1972) study which found this technique used by 23 per cent of the respondents, making it one of the five most used methods. One reason for this difference in findings may be in the 
wording of the questionnaire item. The item in the Johnson (1972) study asked if the clinicians employed "exciting games and conversation" in their management programs. This item was more explicit than asking if the clients practice "under emotional conditions" and may have elicited a greater response rate as a result.

An Emerging Hierarchy in Carryover. It is this investigator's opinion that analysis of these five methodologies: auditory discrimination training (and including other sensory skills), client selfevaluation, automatization of responses, creative dramatics and practicing under emotional conditions, naturally pattern themselves into a hierarchy which may benefit carryover (Figure 3 ). The most basic of these skills appears to be auditory discrimination training. The client's ability to hear the differences between correct and incorrect responses forms the foundation of the hierarchy. This step must be completed before the child is able to evaluate his own production for correctness, i.e., auditory discrimination skills appear to be a prerequisite skill for client self-evaluation. Client self-evaluation, the second stage of the hierarchy, can occur at all levels of production from syllable to conversation. Client self-evaluation is important in that the client must be able to evaluate the correctness of his speech without outside help. This may enable him to know when he is using his correct sound no matter what environment he is in.

Auditory discrimination skills appear to precede the development of client self-evaluation skills yet only 53 per cent of the clinicians who reported using self-evaluation in intervention use auditory discrimination training. Seven clinicians who completed the survey use auditory discrimination training but do not have their client go on to 


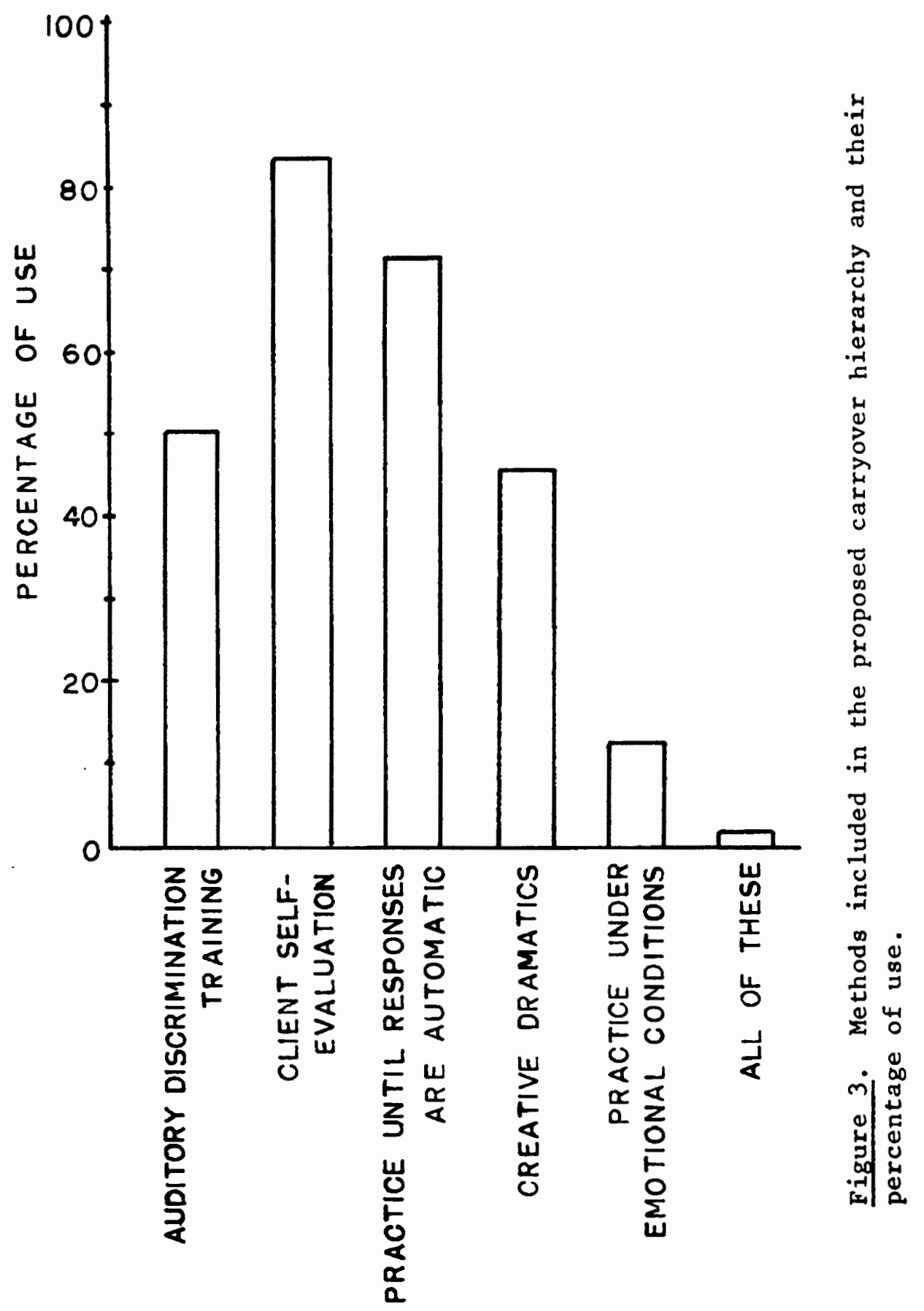


evaluate his/her speech.

The third step in sound acquisition, automatization, can be broken down into three phases: 1) repeated practice in the clinic, 2) story telling, skits and poems (also called "creative dramatics"), and 3) practice under emotional conditions. Of the 126 clinicians reporting data, only two noted using all five of the above mentioned techniques: auditory discrimination training, client self-evaluation, repeated practice, "creative dramatics," and practicing under emotional conditions. The first two steps of the hierarchy, auditory discrimination training and self-evaluation, generally take place within the confines of the clinic room. Automatization begins in the clinic room with practice and repetition until the student is able to produce the target sound without planning or deliberation. Games and contests are situations in which the automatization of the sound is tested. This may be important because, for carryover to be successful, the client must be able to use his target sound correctly in a variety of speaking situations over time.

Behavior Modification. Behavior modification may be used in conjunction with any or all of the methods composing the hierarchy proposed above and may facilitate carryover as a result of specific programming of all components including: planned reinforcement schedules and gradual altering of behavior toward improved articulation skills. Fifty per cent of the 126 respondents reported following a structured behavior modification program making it one of the lesser used techniques (Figure 1). This methodology was evaluated as the third most effective technique for promoting carryover, however (Figure 2). Of the clinicians who rank ordered this technique, 32 per 
cent considered it to be their most effective method (Table I).

No data are available as to why so few clinicians use behavior modification techniques as a management approach. One can speculate as to possible reasons, however. Lack of training in behavior modification techniques may prevent some clinicians from incorporating this approach into their management programs. Another reason may be a perceived lack of time to take baseline data, track client responses or follow structured reinforcement schedules.

Other Methods Reported by the Clinicians. Clinicians noted additional methods which they use in management with articulation disordered clients. One of the techniques mentioned is a timed sound production task in which the clinician times a conversation while counting client errors. The timed segments increase in duration. Bankson and Byrne (1972) studied the effect of a timed correct sound production task on carryover. More specifically, they investigated the effect of a training task that included correct sound production of words as a subject read a word list at increasing rates of speed. Probes of conversational speech indicated that four of the five children in the study showed varying degrees of carryover. The subjects who showed the greatest improvement tended to have the highest number of correct readings. This technique would be appropriate to use at the first phase of automatization where the client must practice until the responses are automatic.

Another approach to carryover mentioned by the clinicians surveyed includes making the program goal oriented. One way of doing this is for the client to work with a contract. Other means of goal orientation can be to have the client monitor his progress or to have 
progress charts for the client to complete. All of these techniques can be followed by reinforcement such as working for a row of stars or an opportunity to play educational games.

Methods Used Outside the Clinic

Many of the techniques, materials and equipment discussed may be used outside the clinic as well as within the clinic. Some techniques used by the clinician, such as sending home assignments or working with the client outside the clinic room, are most often considered to be techniques used in environments other than the speech room.

Working with the Client Outside the clinic. Working with the client outside the clinic room, the fifth most often used and fifth most effective management technique (Figures 1 and 2 ) was used by 63 per cent of the clinicians. Clinicians report "time" as a problem in providing carryover activities, time to work with the client outside the clinic room. They also report working in environments other than the speech room difficult in terms of 1) providing instant reinforcement for correct responses and 2) utilizing a wide variety of environments. A possible advantage of this technique could be that clients may have the misperception that correct articulation is limited to the clinical setting. Working with the client outside of the clinic room may help to alter that view.

Clinician Developed Homework. Assigning homework to the client, the second most popular management technique, was used by 81 per cent of the clinicians (Figure 1). Even so, this method was perceived as the second least effective technique (Figure 2). Some possible problems in promoting carryover, as reported by clinicians, deal with 
client homework and may reflect some of the reasons for its perceived low effectiveness. Several clinicians believe client responsibility is a problem in carryover. More specifically, they blame inconsistent practicing and a lack of motivation to complete homework as reasons for its apparent ineffectiveness. Another factor interfering with client completion of homework may be that students are "too busy" with extracurricular activities to complete their speech homework.

Client Developed Homework. Client developed assignments may help to alleviate some of these problems by placing responsibility of designing and completing homework with the client. By designing his own homework the client may more clearly understand the relationship between using correct speech in the clinic and using correct speech at times other than during the management sessions. However, only 21 per cent of the clinicians have their clients develop their own homework (Figure 1). Reasons for this low figure may be that it is more convenient for the clinician to develop and assign the homework. This was also considered to be one of the least effective methods for promoting carryover (Figure 2).

Reminders in the Client's Environment. The client or clinician may distribute reminders in the client's environment to provide a stimulus for good speech (Engel et al., 1966). In the Johnson (1972) study none of the clinicians surveyed reported distribution of reminders in the environment. One clinician, however, noted instructing the child to put flowers on the bedposts to remind him/her to use good speech. Sixty-two per cent of the Oregon clinicians distribute reminders in the client's surroundings. Of the twelve methods evaluated in this survey, this was the sixth most often used and the eighth most 
effective method (Figures 1 and 2 ). The questionnaire did not elicit specifics concerning the nature of the reminders. Some reminders suggested in the literature are "pictures pasted on the bathroom mirrors" or bookmarks (Engel et a1., 1966).

Language Arts Programs. Sutton (1955) considers an intervention program combined with the student's language arts program as one of the most practical and rewarding methods of reinforcing a pupil's progress. Even so, only 29 per cent of the respondents to this survey reported using this technique (Figure 1). This concurs with Johnson's (1972) results, where 17 per cent of the respondents to her questionnaire combined management with the language arts program. In the present study, this method was not believed to be an effective management technique (Figure 2). Combining these two programs requires time, teacher cooperation and clinician cooperation. Time is required to review the material covered in the language arts program as well as the objectives of the speech program. Planning is needed to blend the two programs into a compatible curriculum, to implement the program, and to carry it through with the client. Speech clinicians are not the only school personnel with busy schedules; classroom teachers also have many demands placed on their time. For these reasons, clinicians may not find combining speech management with the student's language arts classes an efficient or effective technique.

In spite of these drawbacks, the advantages of combining language arts and speech programs are numerous. The language arts program: 1) provides opportunities for the student to use what he has learned in speech sessions; 2) provides a link between classroom material and speech management material; 3) gives the child an opportunity to use 
his correct speech outside the clinic room; and, 4) allows the clinician to judge the client's performance in novel situations (Sutton, 1955).

Client Works with Others. One of the most often discussed carryover practices is that of the client working with individuals other than the clinician (Lillywhite, 1948; Marquardt, 1959; Engel et al., 1966; Carrier, 1970; and Wing and Heimgartner, 1973). Seventy-nine per cent of the clinicians surveyed utilize outside individuals to work with their clients, making it the third most often used technique (Figure 1). Data are contradictory, however, in that all of the respondents to the questionnaire noted outside individuals that they included in management but only 79 per cent reported it as one of their management techniques. One possible reason for this difference may be that only 79 per cent of the clinicians involve outside individuals in direct management of carryover. All of the clinicians may contact individuals at one time or another about the client's progress, thereby involving them in management on an indirect basis. Clinicians ranked this technique as their fourth most effective method for promoting carryover (Figure 2).

People Included in the Management Program

The involvement of outside people in management, the fourth most effective technique, was delineated as to which individuals were included in management programs. More specifically, clinicians were asked if they involved speech aides, classroom aides, classroom teachers, speech pals, peers, or parents in intervention.

Parents. The client's parents, one of the two most often 
included sources of help with intervention, were relied upon for assistance by 94 per cent of the clinicians (Figure 4). They also were considered the most effective source of help (Figure 5). This percentage which includes parents is much higher than the results of the Johnson (1972) study in which only 40 per cent of the clinicians reported parental involvement. One reason for this increase may be due to the advent of the Individualized Educational Program (IEP). Many more parents than before are meeting with clinicians to discuss their children's educational program. In this manner, more parents may be becoming involved, whether directly or indirectly, in the management program. The clinicians who noted involving parents consider them to be the most effective individual included in management.

Clinicians reported a variety of techniques designed to include parents, both directly and indirectly, in management. Some clinicians use an indirect approach, maintaining parental awareness of the client's progress through phone contact or notes sent home. The advantage of indirect involvement may be that it is compatible with busy schedules, is convenient for both the clinician and the parent, and is not as time consuming as direct management. Others rely on direct parental involvement through parent participation in the clinical sessions, in home assignments, or through parent training programs.

Parent training, a technique described in the literature by several authors (Iillywhite, 1948; Carrier, 1970; Fudala, England and Gangoung, 1972; Carpenter and Augustine, 1973; Fudala, 1973; and Wing and Heimgartner, 1973), has been reported to be an effective management practice. Several respondents to the survey placed a qualifier on this view, noting that only concerned, motivated parents are an asset to 


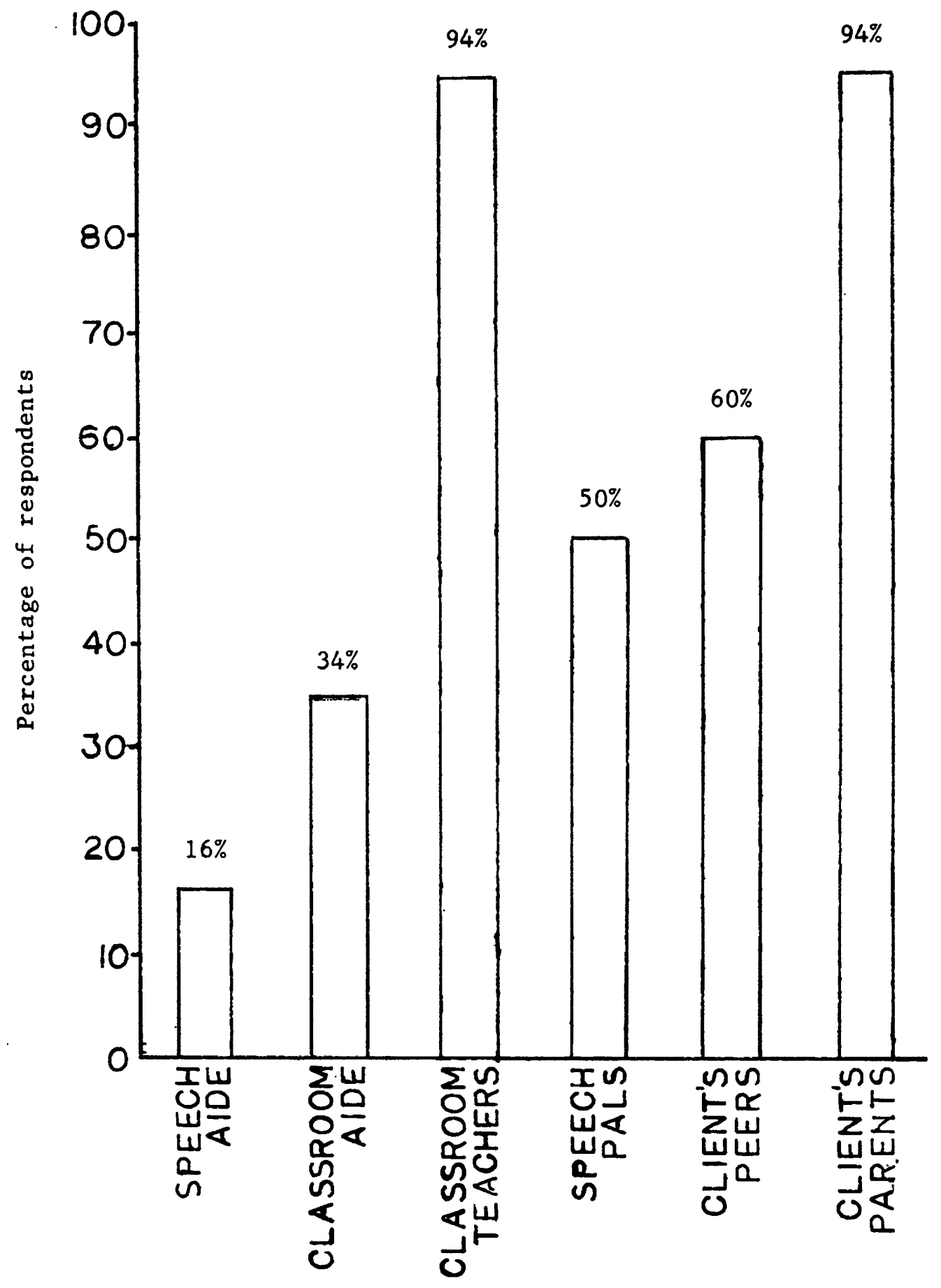

Figure 4. Percentage of clinicians who include a given individual in management. 


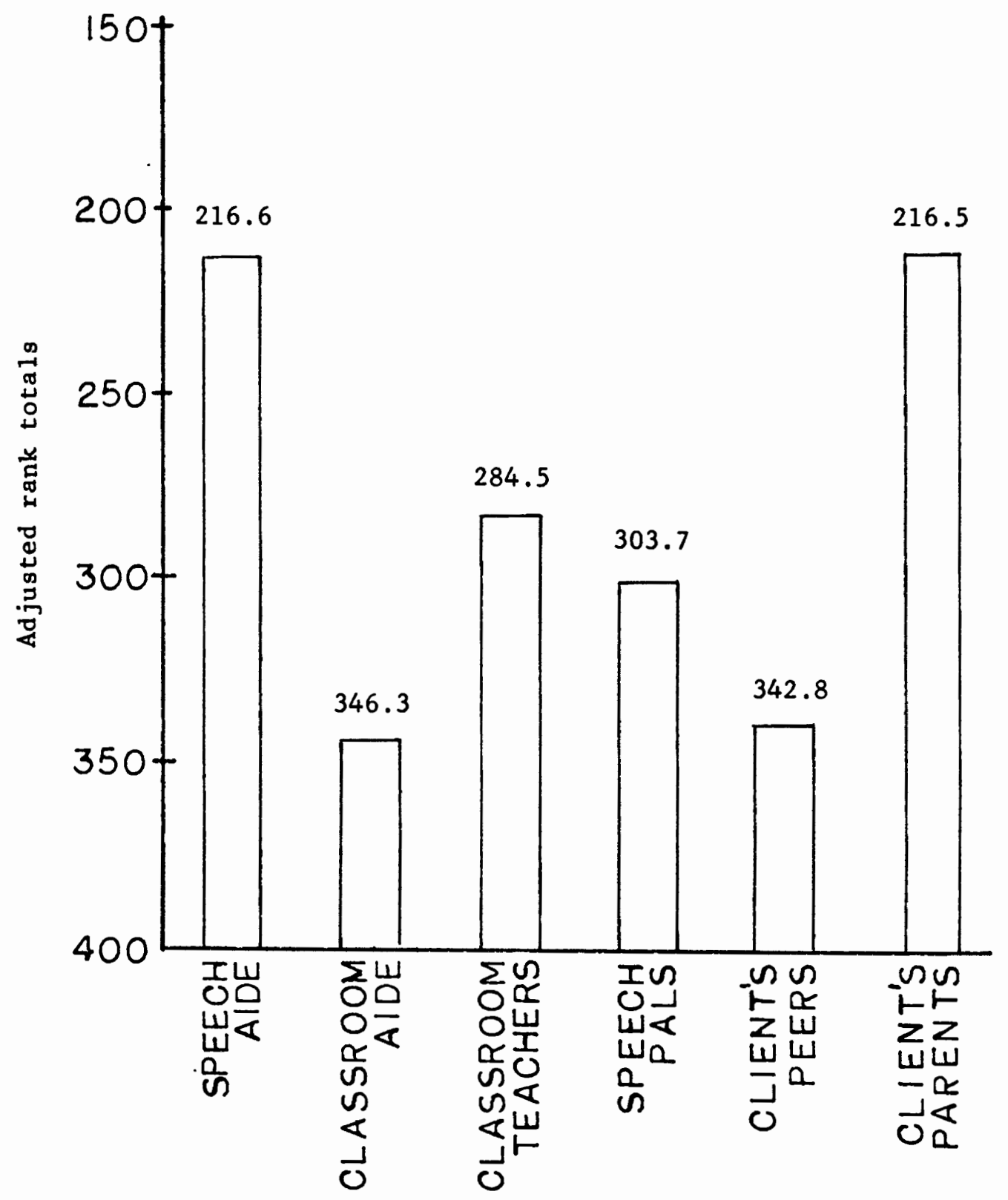

Figure 5. Perceived effectiveness of outside individuals in management to promote carryover. 
management. Parents who do not recognize the need for management or do not support the efforts of the clients or clinicians may be a detriment to intervention. This view is supported by McCroskey and Baird (1971) who did not find parents as a group to make a significant contribution to intervention. They concluded that parents who do not initiate a management program or assume responsibility for intervention represent a different sample than has been used when positive results are reported. Fudala (1973) supports parental involvement as a viable approach to management if parents are willing participants in the programs, are given specific instructions on management techniques and observe at least three management sessions.

The parent training programs reported by the clinicians ranged from parent observation of the management program to parent visits to speech sessions for demonstrations of management techniques to "parent night" where parents were trained by the clinicians to work with their children. Approaches mentioned that are designed specifically for parents included: 1) making "speech games"; 2) monitoring the child at specific times; 3) participating in speech sessions; or, 4) helping the child with his homework assignments. Unfortunately, training programs are time consuming for both the clinician and the parents. Any program developed must be accountable by providing benefits commensurate with cost and energy input. An additional problem, not mentioned in the literature, is the growing number of working mothers and single parent households. Parents may not be able to attend training programs as easily as in the past. However, clinicians appear to be adapting to these changing times by including after school babysitters in the management program. 
Classroom Teachers. Ninety-four per cent of the clinicians reported including classroom teachers in their management programs (Figure 4). This is in contrast to the Johnson (1972) study in which only 7 per cent of the clinicians involved classroom teachers in management. One reason for this difference may be that clinicians and classroom teachers are meeting during I.E.P. conferences to discuss the child's program. These conferences pose an excellent opportunity to inform the teacher concerning the child's management program.

Even though clinicians in Oregon involve teachers in management as often as parents, teachers were not perceived to be as effective (Figure 5). This may be because teachers are often busy and unable to devote individual attention to particular children on a regular basis. Parents, on the other hand, may be with the child more often on a oneto-one basis than the teacher, enabling them to note progress and reinforce correct speech. Also, parents as a group would naturally be more concerned with and aware of their child's progress than the classroom teacher.

Client's Peers. Involving the client's peers, a technique discussed by Engel et al. (1968), is another source of assistance with management. Sixty per cent of the clinicians reported including the client's peers in management, making it the third most often used source of outside help (Figure 4). In contrast, Johnson (1972) found that none of the clinicians she surveyed "employ popular children to supervise practice between the children's visits." Even though this appears to be an often used management technique with Oregon clinicians, it was not perceived to be one of the more effective methods in that it was ranked as one of the two least effective sources of outside 
help (Figure 5). The literature discusses peers as a viable source of assistance but notes that cost accounting is a problem (Groher, 1976). Training the peers to discriminate, evaluate then reinforce appropriately may be more time consuming than the benefits are worth. Also, some teachers may be reluctant to allow non-speech handicapped students to miss classroom activities on a regular basis.

Speech Pals. "Speech pals" is a specific name assigned by Marquardt (1959) to the client's peers who accompany him/her to management sessions as well as assist the client between visits. Evidently there is a distinction in the minds of public school clinicians between speech pals and client peers, in that speech pals were included in 50 per cent of the management programs in contrast to peers, who were included in 60 per cent of the programs (Figure 4). The distinction between "speech pals" and client peers may rest with the perception that "speech pals" are trained members of the client's peer group, while the client's peers are associates with no involvement in the formal management program. Speech pals, though reportedly used less frequently, were considered more effective than the client's peers (Figure 5).

Classroom Aides. Classroom aides were incorporated into the management programs of 34 per cent of the clinicians, but this source of help was considered the least effective of those noted on the questionnaire (Figures 4 and 5). Reasons for this may be that aides are not trained to work with speech disordered children so may not be prepared to evaluate correctness of articulatory skills. Also, aides are not necessarily involved with classroom activities. They may spend the majority of their time preparing materials, may see the children on a 
sporadic basis, or may not have time to consult with the clinicians as to the expectations for various children. For these reasons, their participation may be inconsistent, at best.

Speech Aides. The least used source of outside help, speech aides, was included in 16 per cent of the management programs (Figure 4). In contrast, those who use aides in their programs find them to be an extremely effective source of help (Figure 5). Of the twenty clinicians who evaluated the use of speech aides, ten (50 per cent) ranked them as their most effective source of assistance (Table II). Sixtyone per cent of the respondents to the survey expressed a desire to have a speech aide as part of their program, pointing out the need for effective help with management programs.

One weakness of the questionnaire was that it did not include specific information concerning the number of clinicians who currently have aides. These data would allow for comparison of availability of aides with their frequency of involvement in the management program. Currently, aides compose a part of the program of 17 per cent of the clinicians. Another 61 per cent of the clinicians would like to include aides in their management program. This leaves 22 per cent of the clinicians on which no data are available.

Other Individuals Involved in Carryover. Other sources of help used by the clinicians who responded to the questionnaire include: secretaries, principals, counselors, janitors, librarians, resource room teachers, reading teachers, music teachers and family members other than parents. There are no data regarding how often these other persons are utilized or how they are incorporated into the carryover program. 
Hierarchy of Individuals. Clinicians who include several individuals in their management programs may wish to consider developing a carryover hierarchy. This hierarchy would presuppose that some individuals, such as the school principal or a particular teacher, would be more stressful than parents or peers. Once a hierarchy was established, the student would use this target sound with that person with whom he/she was the most comfortable. After successful use of the target sound with low stress individuals, the client could move up the hierarchy to a more difficult speaking situation. For example, a given client may be comfortable using his new sound at home with his family but may change to old speaking patterns in the classroom. That student would begin using his/her speech with parents and siblings, then possibly with peers in an informal situation such as the playground. The student would gradually develop his skills in a variety of situations before using the target sound in the classroom. This hierarchy may change from student to student but could easily be determined in a brief conversation with the child. Speech assignments could follow the hierarchy in a programmed manner.

\section{Materials and/or Equipment}

Programmed Materials. Clinicians were asked what materials and/or equipment they used in their management sessions. Eighty-two per cent of the respondents reported developing their own carryover programs (Figure 6). This is in contrast with commercial programs, which were used by 52 per cent of the respondents (Figure 6). Clinician developed programs were not only the most popular material or equipment, but were also considered the most effective (Figure 7). 


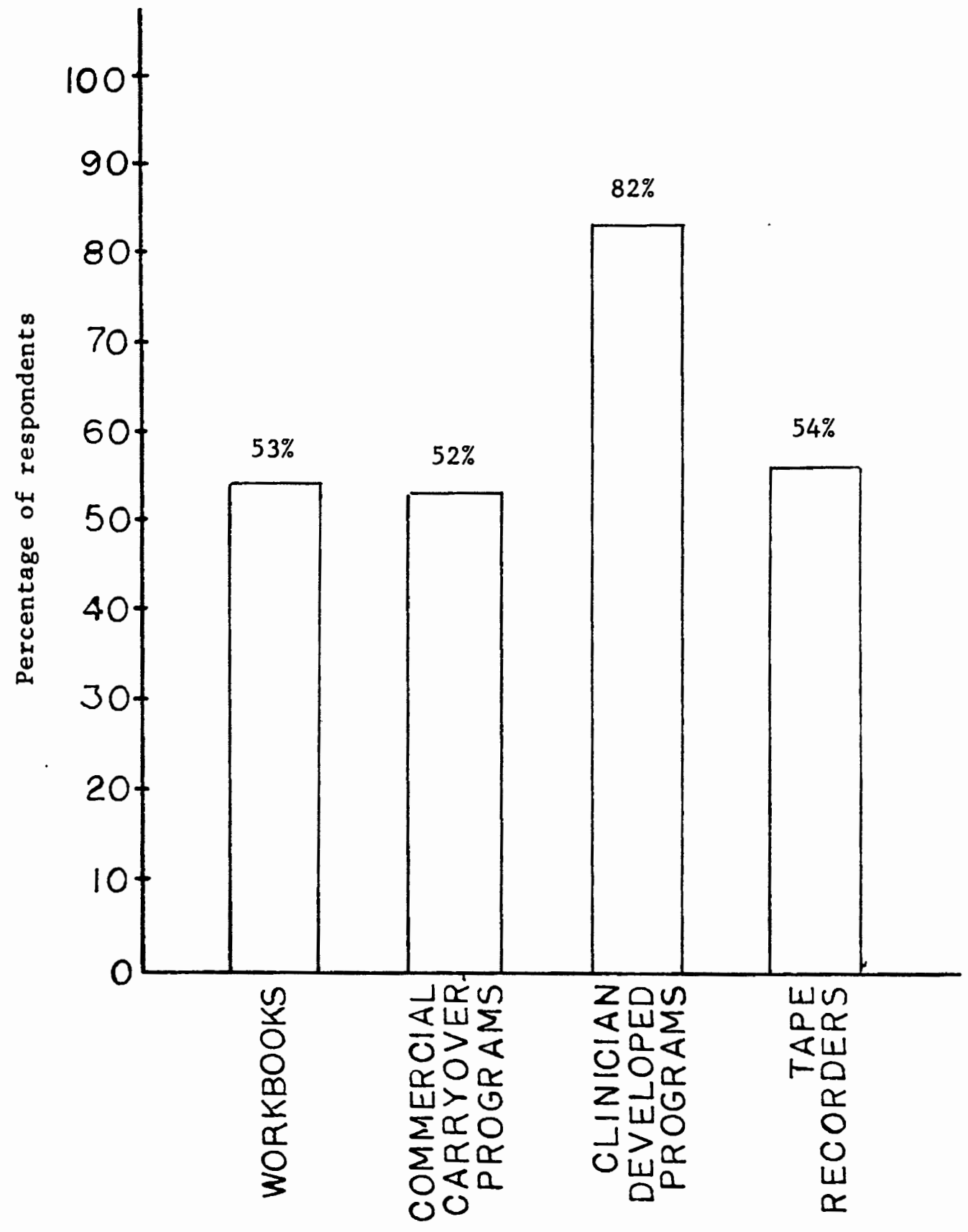

Figure 6. Percentage of clinicians who include given materials or equipment in management. 


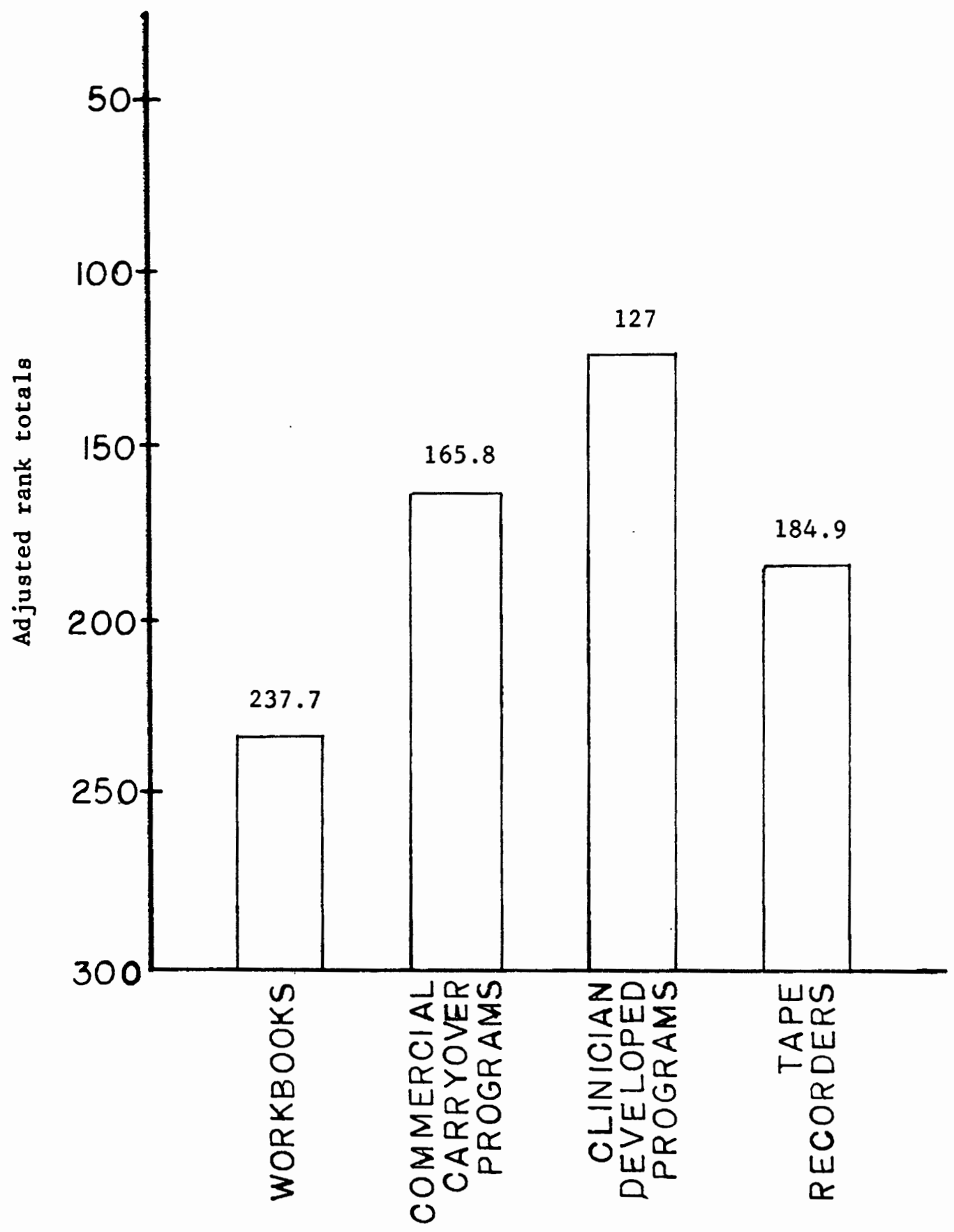

Figure 7. Reported effectiveness of materials and/or equipment used in management to promote carryover. 
Commercial carryover programs were reported to be the second most effective item (Figure 7) but the difference between the two values was considerable. The clinicians who develop their own programs may find them more effective than commercial programs because of program familiarity and the fact that the programs can be tailored to the clinician's particular methods and needs. The perceived effectiveness of commercial programs may indicate a dissatisfaction with the materials currently available. This conclusion was supported by the portion of the questionnaire reporting the problems with carryover management in which clinicians noted a need for more effective commercial programs. This, also, may be a reason so many clinicians reported devising and using their own programs rather than relying on those which are commercially developed.

Tape Recorders. Fifty-four per cent of the clinicians reported using tape recorders in their management sessions, as well as ranking them the third most effective item in this category (Figures 6 and 7 ). In comparison, 17 per cent of the North Dakota clinicians surveyed reported "using tape recorders to demonstrate progress" (Johnson, 1972). A disadvantage of using tape recorders may be that they are expensive, with the price increasing proportionately with the quality of the equipment. On the other hand, tape recorders would provide the client with immediate feedback in the form of a permanent record of his/her production. Also, samples of the client's speech over time could be compared as a means of noting progress.

Workbooks. Workbooks, used by 53 per cent of the clinicians surveyed, were perceived to be the least effective item in this category (Figures 6 and 7). One reason for the poor evaluation of work- 
books may be that the materials must be adapted to the specific needs of the client. An often written comment on the survey was that no two clients are alike. Because of these individual differences, the materials that suit a particular client may not be appropriate for another. An advantage of incorporating workbooks into the management program is that the materials are already prepared, alleviating clinicians from spending preparation time developing their own materials.

Other Materials or Equipment. Other materials or equipment used by clinicians to promote carryover included: language masters, tally counters, worksheets, stimulus cards, games, video-tapes, a Voxcom, an s-indicator, the telephone, tracking sheets, assignment cards, textbooks, library books, conversation charts and speech reminders.

The language master, the most often mentioned of these materials, can allow the student to work independently of clinician supervision. A correct model for imitation by the student is provided via tape recorded master cards. The student records his own production in response to the model; then plays both the model and his production back for comparison. To use this equipment the student must be capable of comparing his production with a tape recorded model and then evaluate that production for correctness. Unfortunately, not all schools have language masters readily available for student use. Also, students must be mature and responsible enough to work independently.

Tally counters, also mentioned by several clinicians, are a convenient and economical means of recording data. These counters can be used by the client as well as the clinician to record correct and/or incorrect productions of the target sound. 


\section{Reported Problems in Attaining Carryover}

Factors reported as key problems in carryover include: 1) the client's attitude; 2) follow. through and support by outside individuals; and, 3) clinical management practices.

\section{Client Attitude}

The client's attitude toward his speech may be the most important factor in the success of management. Fifty-six clinicians reported client attitude toward speech management as a major problem in carryover. It appears that the more motivated, interested and aware the client is, the shorter and more effective the management program. On the other hand, children who are not motivated to change their speech patterns may not: 1) complete homework assignments;2) practice consistently; 3) monitor their speech in a variety of situations; or, 4) attend speech sessions on a regular basis. The clinical impression of those reporting is that these children do not appear to progress as rapidly as the motivated child and may not successfully carryover the skills learned in the clinic to everyday environments.

\section{Follow Through and Support by Outside Individuals}

Eighty-one respondents noted a lack of help from outside individuals as a problem in promoting carryover. Of these eighty-one clinicians, fifty believe poor parental attitudes are a major factor in the failure of carryover. These problems appear when parents: 1) are too busy to work with the child; 2) are unsupportive of the speech program; 3) tell the child his speech is fine the way it is; 4) provide poor speech models; 5) don't follow through with home assignments; or, 6) 
believe speech management to be restricted to the school setting. Even if parents are willing to assist with management, clinicians report that the parent still may not provide consistent reinforcement or reward correct productions of the target sound.

Nineteen clinicians believe the teacher's attitude toward the speech program may influence the carryover process. Clinicians report that teachers are often "too busy" to help, are not trained to evaluate a child's speech production, help in a sporadic manner, or reward incorrect speech patterns. The client's peers also were reported to be a hinderance to progress if those peers reinforce the client's old speech habits and patterns.

\section{Intervention Programs}

Time. Forty-one clinicians believed a major problem with carryover lay with clinical management practices. Of those forty-one clinicians, twenty-six blamed time limitations for their problems. One demand on the clinician's time is administrative duties. Clinicians believe they spend "too much" time with meetings, paperwork and conferences and not enough time on management programs. Another demand for time lies with annual diagnostic, screening and evaluation programs which compose the bulk of the program every fall. Once screening and evaluations are completed, management can begin. Unfortunately, management also seems to demand more time than is available. Time is required to: 1) develop an effective management program; 2) implement that program; 3) see the child on a daily basis; 4) instruct other individuals working with the client; and, 5) carry out a maintenance program once the skills are acquired. 
Caseload Size. Caseload size is reported by clinicians to affect carryover. Encouragement to accept new clients increases the caseload size. Group management, the result of large caseloads and limited time constraints, appears to be a universally used management technique (Chapman et a1., 1961). Sommers (1966) reported group management and individual management to be equally effective. Several respondents to the questionnaire do not agree with this view. Their clinical impression is that carryover is attained much more quickly when the clinician works with the client on an individual basis. Individual management sessions have the advantage of being more flexible in meeting the needs of a particular child and of eliciting a higher rate of response from the client during a given time period. Group management may not be as flexible in that it must meet the needs of several students simultaneously. Also, the larger the group, the fewer the responses elicited from each child. Groups appear to be more cost efficient, however, in that more students are served per clinician hoụr and, in special situations, can be more effective.

Onset of Management. Another view of management involves timing the introduction of correct speech production to the child's physical, intellectual, social and emotional maturational levels. Difficulty arises when determining at what point the child has reached this point of readiness. Some clinicians surveyed advocated a "the younger, the better" policy of correcting errors in speech as soon as they are detected. These clinicians reported the best success with younger children and advocated beginning management with children in kindergarten or the first grade. The philosophy underlying this approach is that the sooner intervention is begun, the easier it will be to change 
habitual behavior and to achieve carryover of that behavior. A second view reported in the survey was that many, if not most, clients selfcorrect without any management (Bralley and Stoudt, 1977). Supporters of this thinking advocate waiting until the child is a third or fourth grader and is more mature and capable of being an active participant in the management process. Older children will demonstrate greater degrees of carryover due to their more mature approach to management. A third philosophy reported in the survey is that age of the client is irrelevant in deciding when to begin management and that age of the child does not influence carryover.

Program Emphasis. Clinicians reported a shift in emphasis that has occurred in management over the last ten years. The major focus of management has moved from articulation disorders to language disorders. Some clinicians support this change in management thrust as an improvement in clinical services. Others do not agree with this trend. They see articulation management as being reduced to a level of nonsignificance with language problems being the only important issue that warrants our "professional expertise." Because of this shift in emphasis clinicians no longer have the time they once did to spend with their articulation disordered clients yet the ultimate goal of management, carryover, remains the same.

\section{Management Practices}

Clinicians, on the average, reported seeing clients for articulation management 2.3 times each week. Clients were seen an average of 50 minutes a week with each session usually 25 minutes in length. Duration of management per week ranged from 20 minutes per week (one 
session twenty minutes in length) to 120 minutes (four sessions, each of which were thirty minutes in length).

Clinicians reported a variation of from one week to 34 weeks of management before the client produced the target sound correctly in conversational speech in the clinic room (Figure 8 ). The mean value was 13 weeks, a finding supported by the Johnson (1972) study in which clinicians reported spending an average of 14 weeks of management before the client produced the target sound in the clinic room. The average length of time needed before the client produced the sounds outside the clinic room, as reported by clinicians in Oregon, was 24.5 weeks with a range of data from five weeks to 72 weeks (Figure 9). This time frame is only half as long as that of 51 weeks reported by Johnson (1972). Clinicians were asked what percentage of their management program was spent on carryover. The most common answer was 20 per cent, as reported by 42 ( 33 per cent) of the 125 respondents to this item. The responses varied greatly with 24 clinicians (19 per cent) spending 10 per cent or less on carryover, 26 clinicians (21 per cent) spending 40 per cent of their program on carryover, 6 clinicians (5 per cent) spending 80 per cent of their program on carryover, and $10 \mathrm{clini-}$ cians ( 8 per cent) spending 90 per cent or more of their program on carryover (Figure 10). 


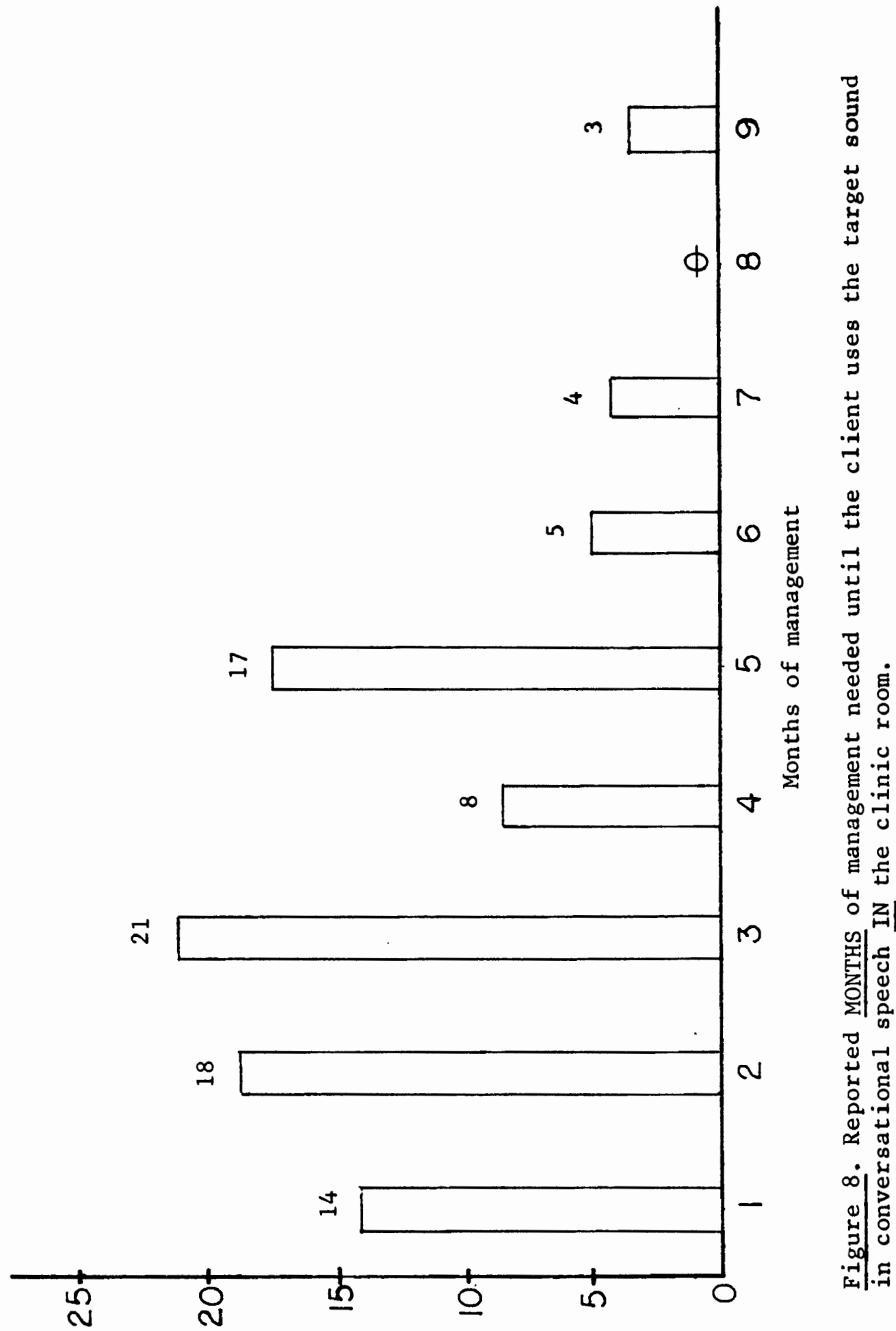

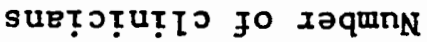




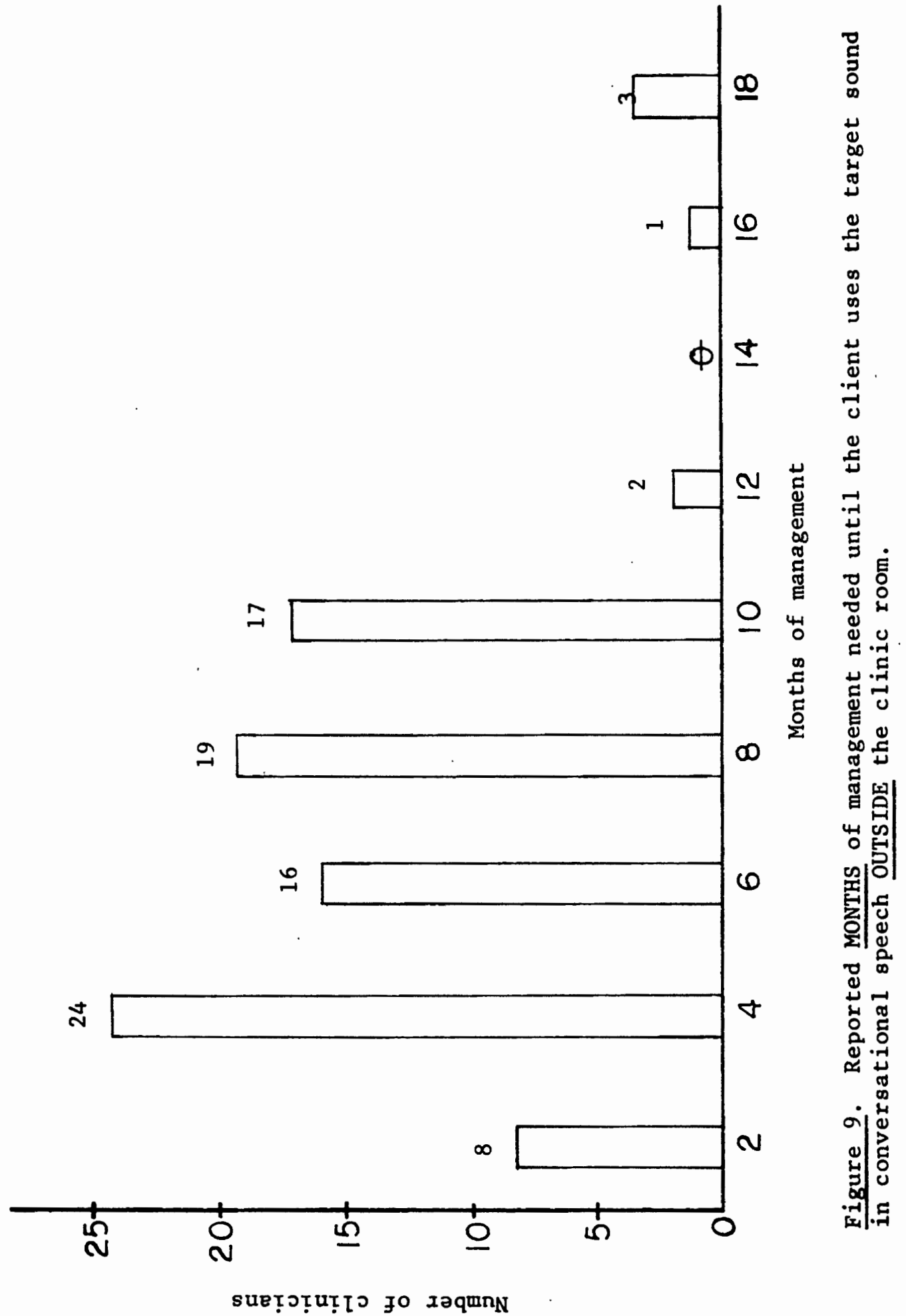




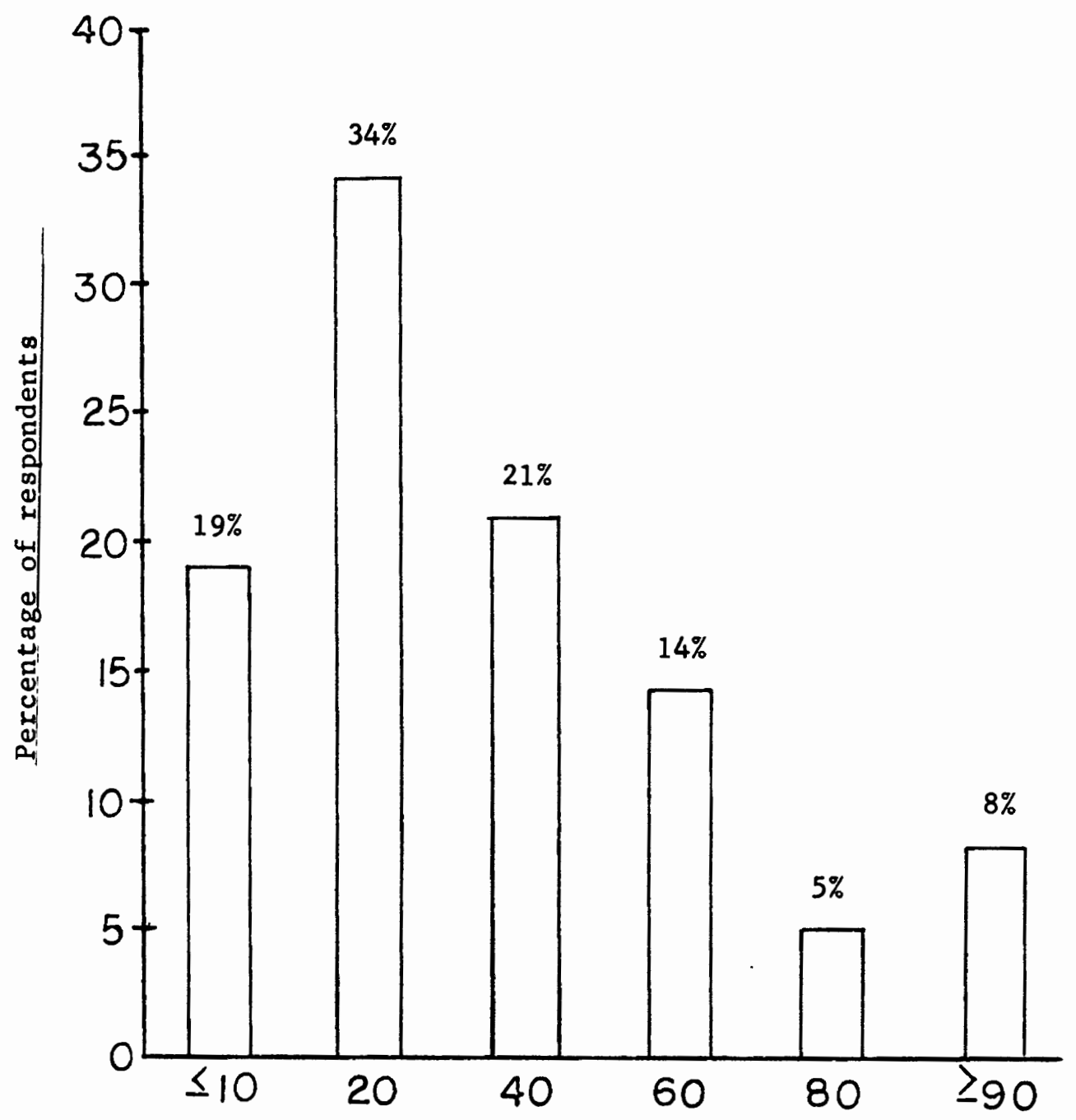

Figure 10. Percentage of articulation management program devoted to carryover, as reported by 125 clinicians. 
CHAPTER V

SUMMARY AND IMPLICATIONS

Summary

Clinicians report that carryover management is one of the most difficult and time consuming problems they face (Johnson, 1972) yet the literature offers little data to assist clinicians in determining what methodologies should be used and which are effective in facilitating carryover. The purpose of this investigation was to determine the type of methodologies utilized by public school clinicians in Oregon to facilitate carryover with clients originally diagnosed as having articulation disorders. A secondary question dealt with the perceived effectiveness of these methodologies.

A description of current practices and trends in articulation management programs was derived from answers to a questionnaire sent to 200 public school clinicians in Oregon. One hundred and twenty-six of the 159 questionnaires returned were used in the tabulation of results. Clinicians in Oregon participating in this study employ a variety of methodologies in their carryover programs. Four management techniques were reported used by 70 per cent or more of the respondents to this survey: client self-evaluation; client completion of homework assignments; client works with individuals other than the clinician; and, client practices until responses are automatic. The four most effective management techniques were: client self-evaluation; client 
practices until responses are automatic; following a structured behavior modification program; and, client works with individuals other than the clinician. The individuals most often included in management were classroom teachers and the client's parents. The most effective individuals, however, were the client's parents and speech aides. Clinician developed carryover programs were reported to be the most often used as well as the most effective material or equipment. Discrepancies in data due to questionnaire design should be studied further.

\section{Research Implications}

Questionnaires of the nature used in this study often generate more questions than are answered. Replication of the study with a wide variety of populations, such as public school clinicians who hold bachelor's degrees or clinicians in other geographical areas, would yield interesting data for comparison.

Many areas of the questionnaire warrant in-depth analysis. For example, one area of research may focus on the client's parents, a source of assistance in 94 per cent of the management programs surveyed. Data from this study concerning the effectiveness of parental involvement are inconclusive without knowledge of parent-client-clinician interactions. Direct parental involvement should be compared to indirect involvement. Techniques used within direct and indirect involvement should also be compared. Parental involvement could then be analyzed within and between these methods. These same questions can apply to the inclusion of any outside individual in management.

A second area amenable to research is the influence of time of onset of management on carryover. Some clinicians advocate a "the 
younger, the better" policy, in which intervention begins as soon as errors are detected. Other clinicians support the philosophy of waiting until the third or fourth grade to begin management, allowing the client to mature physically, intellectually, socially and emotionally. The timing of onset of management may be an important variable in the effectiveness of carryover. Research is needed to determine the optimum time to begin management.

A third area of possible study deals with clinician developed carryover programs. Research to determine the components of these programs may result in the development of more effective commercial programs.

A fourth thrust of research may be the development of a hierarchy of methodologies designed to achieve carryover. Clinicians appear to include numerous management techniques in their programs, but these approaches do not appear to be organized into a cohesive whole. Research is needed to study the relationships of these techniques and to organize them into a usable program.

\section{Clinical Implications}

\section{The University Setting}

Respondents to the questionnaire reported a lack of training at the university level as one of the major problems in developing and implementing carryover programs. This training is difficult to provide in a university clinic where students work with a given client for a term or semester. Students may finish their $\mathfrak{l l i n i c a l}^{\mathrm{l}}$ experience long before the client has reached the stage where the effectiveness of carryover programs can be measured. Training programs may be 
strengthened if a clinician works with a given client throughout the entire management process from initial intake to dismissal following the monitoring of carryover.

Another option available to students, and one more practical for the university setting, is the development of a home maintenance program to be administered by parents. This program may benefit both the student clinician and the client in that it would provide the clinician with experience in developing a carryover program and may assist the client in the transition from the university management program to other environments.

\section{The Public School Setting}

A programmed hierarchial approach to articulation management appears to be more appropriate than the incorporation of a random selection of techniques in promoting carryover. For example, auditory discrimination training logically precedes client self-evaluation yet nearly half of the clinicians who use client self-evaluation did not report including auditory discrimination training in management. A programmed approach would establish the skills necessary for the client to discriminate between his correct and incorrect productions before progressing to the level of client self-evaluation. The client needs these skills in order to monitor his/her own speech when in environments other than the clinic.

Only 50 per cent of the clinicians reported using a structured behavior modification program in management yet it was determined to be the third most effective technique for promoting carryover. Public school clinicians may find combining behavior modification with their 
current management practices to benefit carryover or shorten the time needed to complete the program objectives.

Speech aides, infrequently used but reportedly highly effective, were used by only 16 per cent of the clinicians. Their high effectiveness ranking indicates that clinicians believe inclusion of speech aides would benefit management programs. This may be accomplished through providing articulation on a more frequent basis and/or by allowing more time for the clinician to develop programs, contact outside individuals included in management or follow up on cases at the maintenance leve1. The effectiveness of aides in the speech program is demonstrated in the literature and by the results of this questionnaire. The individual clinician must show the need for an aide in his/her particular program and then lobby for the funding necessary to obtain that aide. 


\section{BIBLIOGRAPHY}

BANKSON, N. W., and BYRNE, M. C., The effect of a timed correct sound production task on carryover. JSHR 15(1), 160-8 (1972).

BERRY, M. F., and EISENSON, J., Speech Disorders: Principles and Practices of Therapy. New York: Appleton-Century-Crofts (1956).

BRALLEY, R. C., and STOUDT, R. J., A five year longitudinal study of development of articulation proficiency in elementary school children. LSHSS 8(3), 176-80 (1977).

BROOKSHIRE, R., Speech pathology and the experimental analysis of behavior. JSHD 32(3), 215-27 (1967).

BUSH, C. S., Creative drama and language experiences: Effective clinical techniques. LSHSS $9(4), 254-8$ (1978).

CARPENTER, R. L, , and AUGUSTINE, L. E., A pilot training program for parent-clinicians. JSHD 38(1), 48-58 (1973).

CARRIER, J. K., A program of articulation therapy administered by mothers. JSHD $35(4), 344-53$ (1970).

CASTEEL, R. L., Personal communication (1979).

CHAPMAN, M., HERBERT, E., AVERY, C., and SELMAR, J., Clinical practice: Remedial procedures. JSHD Monograph Supplement 8, 58-77 (1961).

COSTELLO, J., and BOSLER, S., Generalization and articulation instruction. JSHD 41(3), 359-74 (1976).

DESROCHES, C. P., Speech therapy services in a large school system: A six year overview. LSHSS $7(4), 207-19$ (1976).

DILLMAN, D. A., Mail and Telephone Surveys: The Total Design Method. New York: John Wiley \& Sons (1978).

ENGEL, D., BRANDRIET, S., ERICKSON, K., GRONHOVD, K., and GUNDERSON, G., Carryover. JSHD $31(3), 227-33$ (1966).

FUDALA, J., Using parents in public school speech therapy. LSHSS 4(2), 91-4 (1973).

FUDALA, J. B., ENGLAND, G., and GANGOUNG, L., Utilization of parents in a speech correction program. Exceptional Children 38(5), 407-12 (1972). 
GERBER, A., Goa1: Carry-over, An Articulation Manual and Program. Philadelphia: Temple University Press (1973).

GROHER, M., The experimental use of cross-age relationships in public school speech remediation. LSHSS $7(4), 250-8$ (1976).

GROVE, T., Personal communication (1980).

HAYES, G., Drama is English in action. Language Arts 53, 180-1 (1976).

JOHNSON, M. P., A study of carryover practices among school clinicians in North Dakota. Master's thesis, University of North Dakota (1972).

JOHNSON, W., BROWN, S. F., CURTIS, J. F., EDNEY, C. W., and KEASTER, J., Speech Handicapped School Children. New York: Harper and Row (1967).

LILLYWHITE, H., Make mother a clinician. JSHD 13(1), 61-6 (1948).

MARQUARDT, E., Carry-over with "speech pals." JSHD 24(2), 154-7 (1959).

MCCROSKEY, R. L., and BAIRD, V. G., Parent education in a public school program of speech therapy. JSHD 36(4), 499-505 (1971).

MCINTYRE, B. M., and McWILLIAMS, B. J., Creative dramatics in speech correction. JSHD 24(3), 275-9 (1959).

MCREYNOLDS, L. V., Contingencies and consequences in speech therapy. JSHD $35(1), 12-24$ (1970).

McWILLIAMS, B. J., Adult education for mothers of children with speech handicaps. JSHD 24(4), 408-10 (1959).

MOSER, C. A., and KALTON, G., Survey Methods in Social Investigation. London: Heineman Educational Books Limited (1971).

MOWRER, D. E., Transfer of training in articulation therapy. JSHD $36(4), 427-46$ (1971).

MOWRER, D. E., Methods of Modifying Speech Behaviors. Columbus: Charles E. Merrill Publishing Co. (1977).

NEAL, W. R., Jr., Speech pathology services in the secondary schools. LSHSS $7(1), 6-15$ (1976).

OSGOOD, C. E., The similarity paradox in human learning: A resolution. Psychological Review 56, 132-43 (1949).

POWERS, M. H., Clinical and educational procedures in functional disorders of articulation. In Handbook of Speech Pathology and Audiology. New York: Appleton-Century-Crofts (1977). 
SOMMERS, R. K., Factors in the effectiveness of mothers trained to aid in speech correction. JSHD 27(2), 178-86 (1962).

SOMMERS, R. K., Factors in the effectiveness of group and individual articulation therapy. JSHR $9(2), 144-52$ (1966).

SOMMERS, R. K., FURLONG, A. K., RHODES, F. E., FICHTER, G. R., BOWSER, D. C., COPETAS, F. G., and SAUNDERS, Z. G., Effects of maternal attitudes upon improvement in articulation when mothers are trained to assist in speech correction. JSHD 29(2), 126-32 (1964).

STEER, M. D., Public school speech and hearing services. JSHD Monograph Supplement 8, 78-84 (1961).

SUTTON, E. L., Integrating speech therapy with language arts. JSHD $20(4), 376-9$ (1955).

TUFTS, L., and HOLLIDAY, A., Effectiveness of parents trained as speech therapists. JSHD 24(4), 395-401 (1959).

VAN HATTUM, R. J., Services of the speech clinician in schools:

Progress and prospects. ASHA 18(2), 59-63 (1976).

VAN RIPER, C., Speech Correction: Principles and Methods. New York: Prentice-Ha11 (1978).

VAN RIPER, C., and IRWIN, J. C., in ENGEL, D. C., BRANDRIET, S., ERICKSON, K., GRONHOVD, K., and GUNDERSON, G., Carryover. JSHD $31(3), 227-33$ (1966).

VIA, R. A., Participatory English: Drama. Language Arts 53, 175-9 (1976).

WEBSTER, E. J., Parent counseling by speech pathologists and audiologists. JSHD $31(4), 331-40$ (1966).

WING, D. M., and HEIMGARTNER, L. M., Articulation carryover procedure implemented by parents. LSHSS 4(4), 182-90 (1973).

WINITZ, H., From Syllable to Conversation. Baltimore: University Park Press (1975). 
APPENDIX A

DEMOGRAPHIC DATA

\section{\# Clinicians \\ reporting \\ data}

Mean

value

Range

\section{Caseload size}

per week

123

45 students $12-150$ students

Number of schools

served

3.5 schools $\quad 1-11$ schools

Years clinician worked

in public schools

117

8.3 years

$1-28$ years 


\section{APPENDIX B}

\section{ARTICULATION CARRYOVER QUESTIONNAIRE}

Number of students in the school system (estimate):

Average number of students in your caseload per week:

Number of schools you serve:

Number of years you've worked in the public schools:

Circle the appropriate number. Level of training:
1. Bachelor's
2. Fifth year
3. Master's
4. Doctorate

Circle the appropriate number. Area of training:

1. Speech-language pathologist

2. Audiologist

3. Special Educator

4. Other (specify)

Do you have a caseload which includes articulation disordered clients? 1. yes 2. no

If the answer is "no," you need not continue. Please return this questionnaire so that I can remove your name from my mailing list.

CARRYOVER, for the purposes of this study, is the transfer of newly learned speech skills to all speaking situations outside the clinical setting.

ALL of the following questions deal with CARRYOVER in ARTICULATION MANAGEMENT. Please respond in terms of what you do to promote carryover in your clients with articulation disorders.

1. What percentage of your articulation management program is devoted to facilitating carryover (correct usage of target sounds outside the clinic room)? Circle the appropriate answer.

1. $10 \%$ or less

2. $20 \%$

3. $40 \%$

4. $60 \%$

5. $80 \%$

6. $90 \%$ or more 
2. Which of the following methods do you use to facilitate carryover? Circle the number corresponding to ANY METHOD(S) you use. Rank order ONLY THOSE YOU USE in the right hand column according to their effectiveness, one (1) being the most effective.

CIRCLE those

RANK ORDER :

you use.

1 = most effective

1. follow a structured behavior modification program

2. work with the client outside the clinic room

3. distribute reminders in the client's environment

4. incorporate creative dramatics (poems, stories, plays, etc.) into your management program

5. integrate management with the language arts program

6. use auditory discrimination training

7. have client evaluate himself

8. have client work with others

9. have client complete homework assignments

10. have client develop his own homework assignments

11. have client practice until responses are automatic

12. have client practice under emotional conditions

13. other (specify)

14. other (specify)

15. other (specify)

3. Who do you involve in carryover activities? Circle the number corresponding to any individuals YOU INCLUDE in management. Rank order THOSE YOU INCLUDE in terms of their effectiveness, one (1) being the most effective.

CIRCLE those

RANK ORDER: you use. 1 = most effective

1. speech aide(s)

2. classroom aide(s)

3. classroom teacher(s)

4. speech pals

5. client's peers

6. client's parents

7. other (specify)

8. other (specify) 
4. What materials and/or equipment do you use to promote carryover? Circle the number corresponding to any materials and/or equipment YOU USE. Rank order ONLY THOSE YOU USE in the right hand column in terms of their effectiveness, one being the most effective.

CIRCLE those you use.

1. workbooks

2. commercial carryover programs

3. clinician developed carryover programs

4. tape recorders

5. other (specify)

6. other (specify)

7. other (specify)
RANK ORDER: 1 = most effective

5. Given an ideal situation (i.e.: unlimited time, money, facilities, cooperation, etc.) which of the following that you don't currently use would you ADD to your articulation management program to promote carryover? Circle the number(s) corresponding to any you would ADD to your management program.

CIRCLE those you would ADD.

1. workbooks

2. commercial carryover programs

3. clinician developed programs

4. tape recorders

5. speech aides

6, classroom aides

7. speech pals

8. client's parents

9. creative dramatics

10. structured behavior modification programs

11. client self-evaluation

12. client completion of homework assignments

13. client developed homework assignments

14. other (specify)

15. other (specify)

16. other (specify)

17. other (specify) 
6. How often are articulation cases seen each week?

What is the average length of each session?

7. On the average, how many weeks of management are required before the client begins to produce sounds correctly in conversational speech in the clinic room?

Until he incorporates them into his everyday speech?

8. What do you see as the major problem(s) in attaining carryover?

9. What would you like to tell me that I haven't asked?

Thank you for your help!

Joan Polson 


\section{APPENDIX C}

COVER LETTER AND INFORMED CONSENT FORM

November 5, 1979

An important aspect of any speech/language program is carryover, the transfer of newly learned skills to all speaking situations outside the clinical setting. Your opinions and ideas concerning carryover in your articulation management program are important. Please share them by filling out the enclosed questionnaire. The results of this research will be the basis of my master's thesis currently in progress at Portland State University.

As a speech-language clinician in the public schools you were selected for participation in this study. In order that the results be truly representative of the views of public school clinicians, it is important that you complete and return this questionnaire. This study involves providing written responses to questionnaire items. The questionnaire itself takes about ten minutes to read and fill out. Your participation may help to increase knowledge which may be beneficial to others in the future.

You may be assured of complete confidentiality. The questionnaire has an identification number for mailing purposes only. This is so that I may check your name off the mailing list when your questionnaire is returned.

I would be most happy to answer any questions you might have. Please write me at 4026 N.E. Davis, Portland, Oregon or call me collect at (503) 235-6963.

Thank you for your assistance.

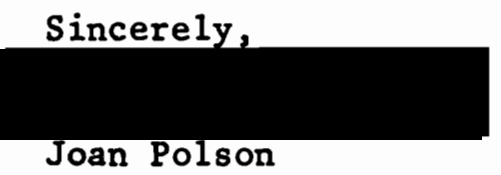

I have read and understand the above information.

Signature:

Date:

If you have any questions about your participation in this study, please contact Richard Streeter, Office of Graduate Studies and Research, 105 Neuburger Ha11, Portland State University, 229-3424. 


\section{APPENDIX D}

\section{FOLLOW-UP POSTCARD}

Dear clinician,

Two weeks ago a questionnaire seeking your opinion on carryover practices in articulation management was mailed to you.

If you have already completed and returned the questionnaire please accept my sincere thanks. If not, please do so today. Because this questionnaire was sent to only a select sample of clinicians in Oregon it is extremely important that you be included in the study if the results are to accurately represent the opinions of public school clinicians in Oregon.

If by some chance you did not receive the questionnaire, or it got misplaced, please call me collect at (503) 235-6963 and I will put another one in the mail to you today.

Thank you, 